\title{
The IRE1/bZIP60 Pathway and Bax Inhibitor 1 Suppress Systemic Accumulation of Potyviruses and Potexviruses in Arabidopsis and Nicotiana benthamiana Plants
}

\author{
Omar Arias Gaguancela, ${ }^{1}$ Lizbeth Peña Zúñiga, ${ }^{1}$ Alexis Vela Arias, ${ }^{2}$ Dennis Halterman, ${ }^{3}$ \\ Francisco Javier Flores, ${ }^{2}$ Ida Elisabeth Johansen, ${ }^{4}$ Aiming Wang, ${ }^{5}$ Yasuyuki Yamaji, ${ }^{6}$ \\ and Jeanmarie Verchot ${ }^{1}$ \\ 'Department of Entomology \& Plant Pathology, Oklahoma State University, Stillwater, OK 74078, U.S.A.; ${ }^{2}$ Departamento de
Ciencias de la Vida y la Agricultura, Universidad de las Fuerzas Armadas-ESPE, Av. General Rumiñahui s/n, Sangolquí,
Pichincha, Ecuador; ${ }^{3}$ Agricultural Research Service, Vegetable Crops Research Unit, U.S. Department of Agriculture ARS,
Madison, WI, U.S.A.; ${ }^{4}$ Department of Plant and Environmental Sciences, University of Copenhagen, Thorvaldsensvej 40,1871
Frederiksberg C, Denmark; ${ }^{5}$ Southern Crop Protection and Food Research Centre, AAFC, 1391 Sandford Street, London,
Ontario N5V 4T3, Canada; and ${ }^{6}$ Laboratory of Plant Pathology, Department of Agricultural and Environmental Biology,
Graduate School of Agricultural and Life Sciences, The University of Tokyo, 1-1-1 Yayoi, Bunkyo-ku, Tokyo 113-8657, Japan
}

Accepted 28 August 2016.

The inositol requiring enzyme (IRE1) is an endoplasmic reticulum (ER) stress sensor. When activated, it splices the bZIP60 mRNA, producing a truncated transcription factor that upregulates genes involved in the unfolded protein response. Bax inhibitor 1 (BI-1) is another ER stress sensor that regulates cell death in response to environmental assaults. The potyvirus $6 \mathrm{~K} 2$ and potexvirus TGB3 proteins are known to reside in the $\mathrm{ER}$, serving, respectively, as anchors for the viral replicase and movement protein complex. This study used green fluorescent protein (GFP)-tagged Turnip mosaic virus (TuMV), Plantago asiatica mosaic virus (PIAMV), Potato virus $Y$ (PVY), and Potato virus $X$ (PVX) to determine that the IRE1/bZIP60 pathway and BI-1 machinery are induced early in virus infection in Arabidopsis thaliana, Nicotiana benthamiana, and Solanum tuberosum. Agrodelivery of only the potyvirus $6 \mathrm{~K} 2$ or TGB3 genes into plant cells activated $b Z I P 60$ and BI-1 expression in Arabidopsis thaliana, N. benthamiana, and S. tuberosum. Homozygous ire 1a-2, ire $1 b-4$, and ire1a-2/ire $1 b-4$ mutant Arabidopsis plants were inoculated with TuMV-GFP or PIAMV-GFP. PIAMV accumulates to a higher level in ire 1a-2 or ire1a-2/ire1b-4 mutant plants than in irelb-4 or wild-type plants. TuMV-GFP accumulates to a higher level in ire1a-2, ire1b-4, or ire 1a-2/ire1b-4 compared with wild-type plants, suggesting that both isoforms contribute to TuMV-GFP infection. Gene silencing was used to knock down bZIP60 and BI-1 expression in $N$. benthamiana. PVX-GFP and PVY-GFP accumulation was significantly elevated in these silenced plants compared with control plants. This study demonstrates that two ER stress pathways, namely IRE1/bZIP60 and the BI-1 pathway, limit systemic accumulation of potyvirus and potexvirus infection.

Corresponding author: J. Verchot; E-mail: Verchot.lubicz@okstate.edu

Genomic sequences were submitted to GenBank database under the following accession numbers: chcBI, accession number KX459425; chcbZIP60a, KX459426; and chcbZIP60b, KX459427.

*The $\boldsymbol{e}$-Xtra logo stands for "electronic extra" and indicates that one supplementary figure and three supplementary tables are published online.

(c) 2016 The American Phytopathological Society
Silencing BI-1 expression also resulted in systemic necrosis. These data suggest that ER stress-activated pathways, led by IRE1 and BI-1, respond to invading potyvirus and potexviruses to restrict virus infection and enable physiological changes enabling plants to tolerate virus assault.

The endoplasmic reticulum (ER) has multiple functions, including calcium storage, protein synthesis, protein folding, membrane lipid synthesis, and cell-death regulation. RNA viruses infecting animals and plants depend upon the biosynthetic and transport properties of the ER-Golgi network for success in replication and completion of their infection cycles (Grangeon et al. 2012a and b ; Laliberté and Sanfacon 2010). Invading RNA viruses take advantage of the large malleable surface that the ER presents. Viruses will stimulate lipid synthesis to further expand the ER surface area and remodel portions of the ER into protected microenvironments for replication (Laliberté and Sanfacon 2010; Sasvari and Nagy 2010; Verchot 2011). Cellular chaperones within the ER lumen or tethered to its surface facilitate protein folding, disulfide bond formation, and other protein modifications. ER stress sensors that span the lipid bilayer recognize malformed proteins and changes in calcium homeostasis within the ER lumen or respond to environmental stressors that cause the ER to malfunction. These sensors initiate signaling cascades and activate gene expression to enhance the protein-folding capacity of the ER with the goal of restoring homeostasis. This is known as the unfolded protein response (UPR) (Ruberti et al. 2015). Malformed proteins that cannot be refolded are then exported from the ER for degradation, typically via the proteasome or autophagic machinery. Chronic ER stress that cannot be resolved by upregulation of UPR can lead to apoptosis in mammals and cell death in plants (Adamakis et al. 2011; Benali-Furet et al. 2005; Williams et al. 2014). The decision made by cells between survival and death in the face of virus infection is intriguing and recent data has been presented showing that plant viruses interact with the ER stress-signaling machinery (Lu et al. 2016; Ye and Verchot 2011; Ye et al. 2011, 2013; Zhang et al. 2015).

The plant ER network contains three transmembrane sensors of ER stress that include the inositol requiring enzyme 1 (IRE1), bZIP17, and bZIP28 (Chen and Brandizzi 2013a; Iwata 
and Koizumi 2012). IRE1 is the most conserved component of the UPR across eukaryotes. Yeast has one copy, while plants and mammals have two copies, IREI $a$ and IREIb, of this gene (Duwi Fanata et al. 2013). IRE1 in mammals binds to apoptosisregulating proteins, including $\mathrm{Bcl} 2$-associated $\mathrm{X}(\mathrm{BAX})$ and Bcl2-antagonist/killer 1 (BAK), and is known to cause degradation of selected microRNAs that repress translation of targeted caspases (Buytaert et al. 2006; Castillo et al. 2011; Scorrano et al. 2003). IRE1-dependent decay of mRNA (RIDD) was shown first in mammals and Drosophila spp. and, most recently, in plants (Bhattacharyya et al. 2014; Deng et al. 2013; Hollien et al. 2009). RIDD selectively targets mRNA for degradation and reduces the translation load in cells that are under stress. In mammals, prolonged activation of RIDD can lead to cell death. One arm of the IRE1-mediated events in plants involves splicing of the bZIP60 transcription factor mRNA by the ER stress-activated IRE1 (Humbert et al. 2012; Moreno et al. 2012; Nagashima et al. 2011; Parra-Rojas et al. 2015). The fulllength unspliced bZIP60u has a putative transmembrane domain, resides in ER, and its function is not known. The activity of IRE1 splicing removes a 23-nt segment from the bZIP60 transcript. The spliced $b Z I P 60 s$ lacks the putative transmembrane domain and is the active transcription factor that functions in the nucleus during UPR (Nagashima et al. 2011). The truncated bZIP60s protein enters the nucleus, where it activates UPR-related genes, including protein foldases that serve to reduce misfolded proteins in the ER. The bZIP17 and bZIP28 are transcription factors that typically respond to abiotic stresses, such as salinity, drought, and heat. These two factors have transmembrane domains and reside in the ER. Upon recognition of stress, the S1P protease cleaves the transmembrane domain enabling them to move to the nucleus, where they activate UPR-regulated genes and reduce misfolded proteins in the ER (Duwi Fanata et al. 2013; Henriquez-Valencia et al. 2015; Iwata and Koizumi 2012). These UPR transcription factors, bZIP60s, bZIP28, and bZIP17, recognize promoters that contain ER stress responsive cis-element I (ERSE-I) or the plant-unfolded protein response element (P-UPRE) genes. Research has shown that more than one of these bZIP transcription factors can be activated by an environmental trigger, indicating that these pathways provide some compensatory abilities, and can coordinate their responses to changing environments (Liu and Howell 2016).

Bax inhibitor 1 (BI-1) is an ER-localized sensor that is conserved across eukaryotes. It is most often described as a "cell death suppressor" because it functions in mammals to inhibit BAX-mediated cell death through monitoring changes in $\mathrm{ER} \mathrm{Ca}^{+2}$ stores (Buytaert et al. 2006; Chae et al. 2004; Ishikawa et al. 2013). BI-1 binds cytochrome P450, interacts with IRE1 $\alpha$ in mammals and controls autophagy (Chae et al. 2004). In plants, BI-1 is shown to suppress programmed cell death (PCD) in response to a wide range of stimuli (Watanabe and Lam 2008a, 2009). Arabidopsis BI-1 interacts with calmodulin 7, affects $\mathrm{Ca}^{+2}$ homeostasis during stress, and binds cytochrome $b_{5}$ in the ER (Nagano et al. 2009; Weis et al. 2013). It is not known whether BI-1 directly binds with IRE1 to monitor PCD signaling pathways. AtBI-1 is another eukaryotic ER stress sensor that responds to changes in ER calcium stores and regulates PCD (Watanabe and Lam 2008a and b). In plants, it is proposed to either regulate IRE1 directly or factors that lie downstream of IRE1 (Watanabe and Lam 2009).

Several studies demonstrated that the IRE1/bZIP60 pathway regulates infection of certain plant RNA viruses via interactions with key ER-associated viral proteins. These include the triple gene block 3 (TGB3) movement protein of Potato virus $X$ (PVX; genus Potexvirus), the 6K2 membrane binding protein of Turnip mosaic virus (TuMV; genus Potyvirus), the P10 outer capsid protein of Rice black-streak dwarf virus (RBSDV; genus
Reovirus), and the p11 movement protein of Garlic virus $X$ (GarVX; genus Allexivirus). PVX TGB3 is an ER-localized factor that functions in coordination with other viral movement proteins to aid the trafficking of viral RNA between neighboring cells (Bamunusinghe et al. 2009; Ju et al. 2008). A Histagged TGB3 expressed from the viral genome or from a binary plasmid fused to either the Cauliflower mosaic virus $35 \mathrm{~S}$ or Nos promoters was shown to specifically induce transcription of bZIP60 and BiP. Other PVX proteins were examined and none were shown to interact with this pathway. The levels of TGB3 expression (and other viral proteins) from the PVX genome and heterologous $35 \mathrm{~S}$ promoter were comparable, indicating that activation of the IRE1/bZIP60 pathway was specifically due to an activity of the viral TGB3 protein. Since the synthesis of internal membranes can often be enhanced by RNA virus infection, additional experiments demonstrated that transcription of BiP was specifically elevated, while other molecular markers existing along the prevacuolar membrane system (SYP21, SYP41, and SYP61) were relatively unaltered. Comparison of transcriptional responses to PVX and Tobacco mosaic virus (TMV) infection determined that bZIP60 and BiP induction was an early response to PVX and not TMV infection. When the PVX TGB2 and TGB3 proteins were introduced into the TMV genome, experiments revealed that the recombinant TMV accumulated to lower levels than the wild-type TMV and that TMV-TGB3 only stimulated expression of BiP. A mutation eliminating the TGB3 transmembrane domain failed to elicit BiP expression, suggesting that ER localization is important for gene activation. Knockdown of the full-length $b Z I P 60$ via silencing alters the levels of virus accumulation in systemic tissue (Ye and Verchot 2011; Ye et al. 2011, 2013). The TuMV 6K2 protein anchors the viral RNA to the ER via the viral-linked protein (termed VPg) at the $5^{\prime}$ end of the genome (Cotton et al. 2009; Grangeon et al. 2012b) and recruits the viral replicase and host proteins to assemble viral replication centers (Dufresne et al. 2008a and b; Grangeon et al. 2010). One study demonstrated that the TuMV $6 \mathrm{~K} 2$ and not other TuMV proteins stimulates accumulation of the spliced bZIP60 mRNA as well as $\mathrm{BiP}$ in Arabidopsis leaves. In this report, the $6 \mathrm{~K} 2$ protein did not directly bind to IRE1a or IRE1b but, nonetheless, caused the noncanonical splicing of the $b Z I P 60$ mRNA by IRE1a/b. Research showed that accumulation of the truncated bZIP60 protein resulted in higher levels of virus accumulation in systemic leaves (Zhang et al. 2015). RBSDV P10 protein has three predicted transmembrane domains, associates with the ER, and aids assembly of intermediate virus particles (Sun et al. 2013). Experiments showed that the RBSDV P10 specifically stimulates expression of bZIP60 and BiP in rice leaves. A mutation eliminating ER association of P10 also eliminated gene induction, indicating that, similar to TGB3, protein association with the ER enables a mechanism to activate $b Z I P 60$ and BiP gene expression (Sun et al. 2013). The GarVX p11 movement protein also associates with the ER and was suggested to stimulate bZIP60 and BiP in a manner similar to PVX TGB3 (Lu et al. 2016). However, it was not clear whether the IRE1/bZIP60 pathway is generally important for potexvirus, reovirus, or potyvirus replication and movement.

This study provides a comparative analysis of four viruses belonging to the potexvirus and potyvirus genera in Arabidopsis thaliana, Nicotiana benthamiana, and Solanum tuberosum to examine the role of the IRE1/bZIP60 pathway in virus infection. The potexvirus TGB3 and potyvirus $6 \mathrm{~K} 2$ small membrane proteins reside in the ER, and we hypothesize that they are responsible for inducing bZIP60-related UPR in N. benthamiana and Arabidopsis (Ye et al. 2011; Zhang et al. 2015). Agroinfiltration was employed to deliver the PVX TGB3, Plantago asiatica mosaic virus (PlAMV) TGB3, TuMV 6K2, and Potato virus $Y$ 
(PVY) 6K2 genes to Arabidopsis, N. benthamiana, and Solanum tuberosum plants for side-by-side comparison. In addition, we look more closely at the role of cell-death regulation at the ER, by studying changes in $B I-1$ expression in response to virus infection. We report very different patterns of virus infection in

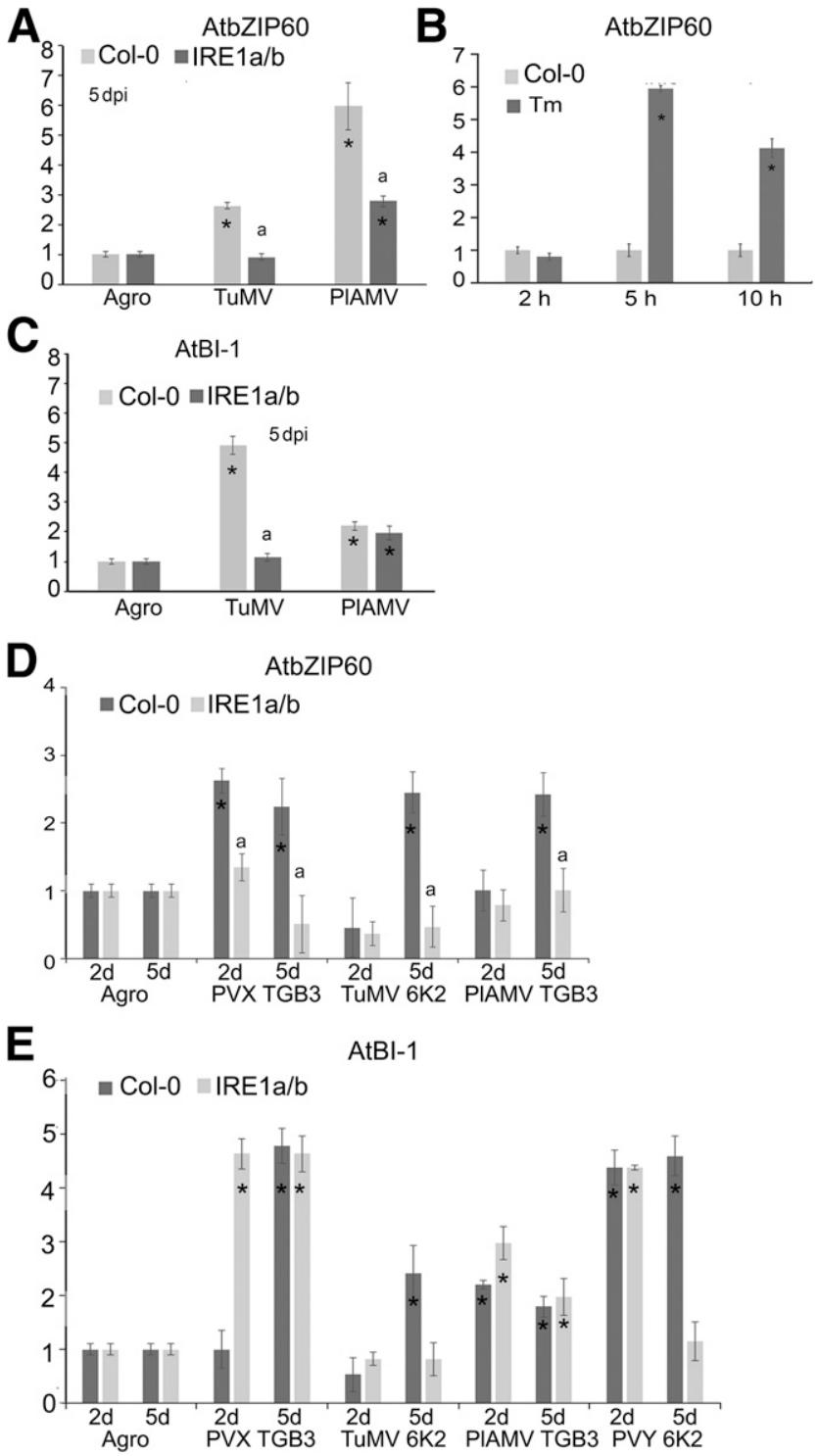

Fig. 1. Virus induction of AtbZIP60 and AtBI-1 in Arabidopsis leaves. Graphs represent data obtained at 2 and 5 days postinoculation, as indicated on the $x$ axis, and show relative levels of AtbZIP60 or AtBI-1 transcripts accumulating in wild-type Col-O or irela-2/irelb-4 mutant Arabidopsis plants. Control involved using agrobacterium alone. Data presented are representative of between three and five independent experiments. Data shown are mean \pm standard deviation of three samples within each experiment. In each histogram, the asterisk (*) identifies colored bars that were statistically different from the same colored bars of the control sample treated with agrobacterium alone, demonstrating elicitor induced gene expression $(P<0.5)$. A lower case letter a indicates a statistical comparison in which the ire 1a-2/ire $1 b-4$ mutant Arabidopsis plants were statistically different from the wild-type plants in the following treatment with the same elicitor $(P<0.1)$. A and $\mathbf{C}$, TuMVGFP or PlAMV-GFP delivery by agroinfiltration and quantitative reverse transcription-polymerase chain reaction (qRT-PCR) detected AtbZIP60 or AtBI-1 transcripts. B, Leaves were treated with $5 \mu \mathrm{g}$ of tunicamycin $(\mathrm{Tm})$ per milliliter, which is a known positive control for induction of AtbZIP60, between 2- and $10 \mathrm{~h}$ postinfiltration. D and E, Potato virus $X$ (PVX) TGB3, Plantago asiatica mosaic virus (PlAMV) TGB3, Turnip mosaic virus (TuMV) $6 \mathrm{~K} 2$, or Potato virus $Y$ (PVY) $6 \mathrm{~K} 2$ were delivered by agroinfiltration and qRT-PCR detected AtbZIP60 or AtBI-1 transcripts. Statistical analysis was carried out using REST2009 software. response to changes in IRE1, bZIP60, and BI-1 expression, suggesting that these vital ER stress regulators monitor virus infection.

\section{RESULTS}

\section{bZIP60 and $A t B I-1$ induction}

in response to potexvirus and potyvirus infection.

To compare the ability of potyviruses and potexviruses to activate the UPR machinery, we measured AtbZIP60 and AtBI-1 transcript levels in wild-type Col-0 and ire 1a-2/ire1b-4 double mutant Arabidopsis plants following agroinoculation with green fluorescent protein (GFP)-tagged PlAMV (genus Potexvirus) and TuMV (genus Potyvirus). The double mutant ire 1a-2/ire1b-4 is a well-characterized line in which T-DNA insertions knock out expression of IREla, knock down expression of IREIb, and eliminate bZIP60 mRNA splicing, regardless of the biotic or chemical stressor applied (Deng et al. 2011; Moreno et al. 2012; Zhang et al. 2015). Systemic fluorescence due to PlAMV-GFP or TuMV-GFP was visible within 10 days postinoculation (dpi) (Yamaji et al. 2012). RNA was extracted from the virus-inoculated leaves at $5 \mathrm{dpi}$ for real time and quantitative reverse transcription polymerase chain reaction (qRT-PCR), which was used to monitor accumulation of the combined full-length and truncated bZIP60 transcripts (Supplementary Table S1). In Col-0 plants, AtbZIP60 transcripts were approximately 2.6-fold higher following TuMVGFP infection and sixfold higher following PlAMV-GFP infection than in control Col-0 leaves treated with agrobacterium alone (Fig. 1A) $(P<0.05)$. Previous studies using TuMV-GFP and PVX-GFP also reported 2.5- to eightfold stimulation of AtbZIP60 transcripts (Ye and Verchot 2011; Ye et al. 2011; Zhang et al. 2015). Tunicamycin (Tm) is a chemical inducer of UPR that is a well-known activator of the IRE1/bZIP60 pathway (Duwi Fanata et al. 2013; Iwata and Koizumi 2012). As an external control to validate our ability to assay AtbZIP60 induction, we treated leaves with $5 \mu \mathrm{g}$ of Tm per milliliter and, using the same qRT-PCR assay, we found that the relative levels of AtbZIP60 transcripts increased significantly between 2 and $5 \mathrm{~h}$ compared with the untreated control in wild-type Col-0 leaves (Fig. 1B).

AtbZIP60 induction by PlAMV-GFP or TuMV-GFP depended upon IREla/b genes. The combined levels of full-length and truncated AtbZIP60 transcripts was significantly higher in wild-type Col-0 plants than homozygous ire 1a-2/ire $1 b-4 \mathrm{mu}-$ tant plants infected with PlAMV-GFP or TuMV-GFP (Fig. 1A) $(P<0.05)$. Notably, AtbZIP60 transcript levels remained somewhat higher in irela-2/ire lb-4 mutant lines infected with PlAMV-GFP compared with similar plants treated with agrobacterium alone. In studies employing abiotic stressors, some background gene induction occurs as the result of bZIP28 or bZIP17 compensating for the loss of IRE1 functions stimulating ER stress-related transcripts (Liu and Howell 2016). These data suggest that potexviruses could uniquely involve additional ER stress-transcription pathways (such as bZIP28 and bZIP17) that are worthy of further investigation.

Induction of $A t B I-1$ transcripts was not necessarily dependent upon IRE1a/b. In wild-type Col-0 leaves at $5 \mathrm{dpi}, A t B I-1$ transcripts were two- and fivefold, respectively, more abundant in PlAMVGFP and TuMV-GFP inoculated leaves than in leaves treated with agrobacterium alone (Fig. 1C) $(P<0.05)$. In ire la-2/ire $1 b-4$ mutant leaves, the level of AtBI-1 transcripts was also induced approximately twofold in PIAMV-GFP infected leaves (Fig. 1C) $(P<0.05)$. However, in TuMV-GFP-infected leaves, transcript levels were comparable to the agrobacterium-treated control samples (Fig. 1C) $(P>0.10)$.

The abilities of the PVX TGB3, TuMV 6K2, PlAMV TGB3, and PVY $6 \mathrm{~K} 2$ genes to induce expression of AtbZIP60 and 
AtBI-1 were compared in wild-type and irela-2/1b-4 mutant Arabidopsis plants. Since Arabidopsis is not a typical host for PVX or PVY, we predicted that the observed level of AtbZIP60 and AtBI-1 induction could involve a nonhost interaction resulting in a stress response that is unlike the level of induction for TuMV 6K2 or PlaMV TGB3. RT-PCR and agarose gel electrophoresis were carried out to confirm expression of the viral elicitors in the infiltrated leaves (data not shown), while qRT-PCR analysis was carried out to quantitatively examine changes in AtbZIP60 and AtBI-1 transcript levels. At 2 days following agrodelivery of PVX TGB3, AtbZIP60 transcripts were elevated approximately 2.6 -fold above the control agrobacteriuminfiltrated wild-type Col-0 leaves (Fig. 1D) $(P<0.05)$, but comparable values (1.35 and 1.0) were derived in ire 1a-2/ire $1 b-4$ mutant leaves $(P>0.1)$. At 5 days, in wild-type Col-0 leaves treated with PVX TGB3, TuMV 6K2, and PlAMV TGB3, AtbZIP60 transcripts were elevated to levels that were between 2.2- and 2.5-fold $(P<0.05)$ but remained unaltered in ire 1a-2/ire 1b-4 mutant leaves. These data indicate that these potexviral and potyviral small membrane-binding proteins activate UPR via the IRE1/bZIP60 pathway.

Early induction of AtBI-1 expression by a viral elicitor appears to be independent of IRE1a/b. At 2 days, AtBI-1 transcripts were 4.4- and 4.6-fold above the control in PVY 6K2 infiltrated wild-type and irela-2/ire $1 b-4$ mutant leaves and in PVX TGB3-infiltrated ire 1a-2/ire1b-4 mutant leaves (Fig. 1E) $(P<0.05)$. AtBI-1 transcript levels were two- to threefold higher in both wild-type and mutant leaves treated with PlaMV TGB3. TuMV 6K2-treated leaves did not show much change at 2 days.

At 5 days, AtBI-1 transcripts remained elevated in PVX TGB3-infiltrated wild-type and ire la-2/ire 1b-4 mutant leaves and in PVY 6K2 wild-type leaves but declined in the ire1a-2/irelb-4 mutant leaves to levels that were comparable to the control. In PIAMV TGB3-treated wild-type Col-0 and ire 1a-2/ire $1 b-4$ mutant leaves, the levels of AtBI-1 transcripts declined to 1.8- to 2.0fold above the control (Fig. 1E) $(P \leq 0.05)$. In TuMV 6K2-treated wild-type Col-0 but not irela-2/ire 1b-4 mutant leaves, AtBI-1 transcripts increased at 5 days to 2.4-fold above the control (Fig. $1 \mathrm{E})(P \leq 0.05)$. These combined data indicate that the viral elicitors that activate $b Z I P 60$ expression in an IRE1-dependent manner also activate $A t B I-1$ transcription. However, AtBI-1 induction appears to be IRE1-independent, since we see induction in the irela-2/irelb-4 mutant plants.

\section{Viral elicitors of IRE1-mediated bZIP60 mRNA splicing in Arabidopsis.}

Since AtbZIP60 mRNA is unconventionally spliced in the cytoplasm by IRE1, we employed the bZIP60 UR primer that spans each side of the 23-nt splice site along with a forward primer that would amplify only the spliced AtbZIP60 transcripts (AtbZIP60s) to quantify the abundance of spliced mRNAs. We also employed a reverse primer that contains sequences within the spliced region along with the same forward primer, which would amplify sequences that represent abundance of fulllength AtbZIP60 (AtbZIP60u) transcripts (Fig. 2A) (Deng et al. 2011; Moreno et al. 2012; Zhang et al. 2015). Agroinfiltration was used to deliver constructs expressing the TuMV 6K2, PlAMV TGB3, or the PVX TGB3 proteins to wild-type and ire 1-2/ire1b-4 mutant Arabidopsis leaves. RNA was extracted from the elicitor-treated leaves at 2 and 5 days and qRT-PCR was used to monitor the accumulation of the UPR-related bZIP60 transcripts. We expected to observe higher levels of AtbZIP60s transcripts in the wild-type plants than in plants that were defective for IREIa/b genes.

At 2 days, the abundance of AtbZIP60s transcripts in PIAMV TGB3 and PVX TGB3 was significantly above the levels of
bZIP60u transcripts in the same wild-type Col-0 plants. The levels of AtbZIP60s were also greater than the control plants $(P<0.05)$. In ire 1-2/ire 1b-4 mutant Arabidopsis leaves, AtbZIP60s transcripts were comparable to the control leaves (Fig. 2B). At 5 days, the abundance of AtbZIP60u and AtbZIP60s transcripts in PlAMV TGB3 and TuMV 6K2 leaves continued to increase (Fig. 2B). AtbZIP60s transcripts were approximately

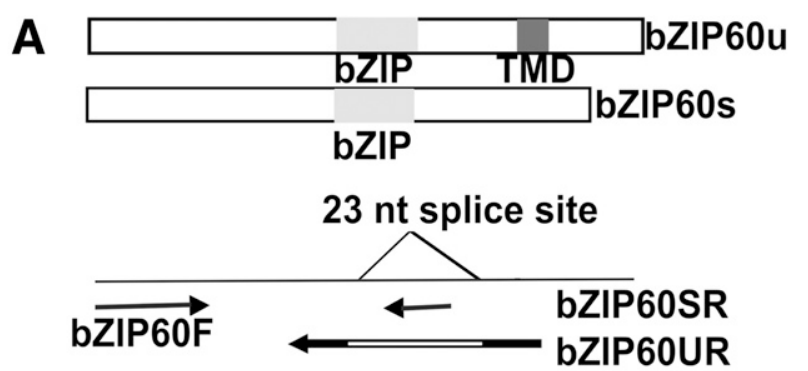

B
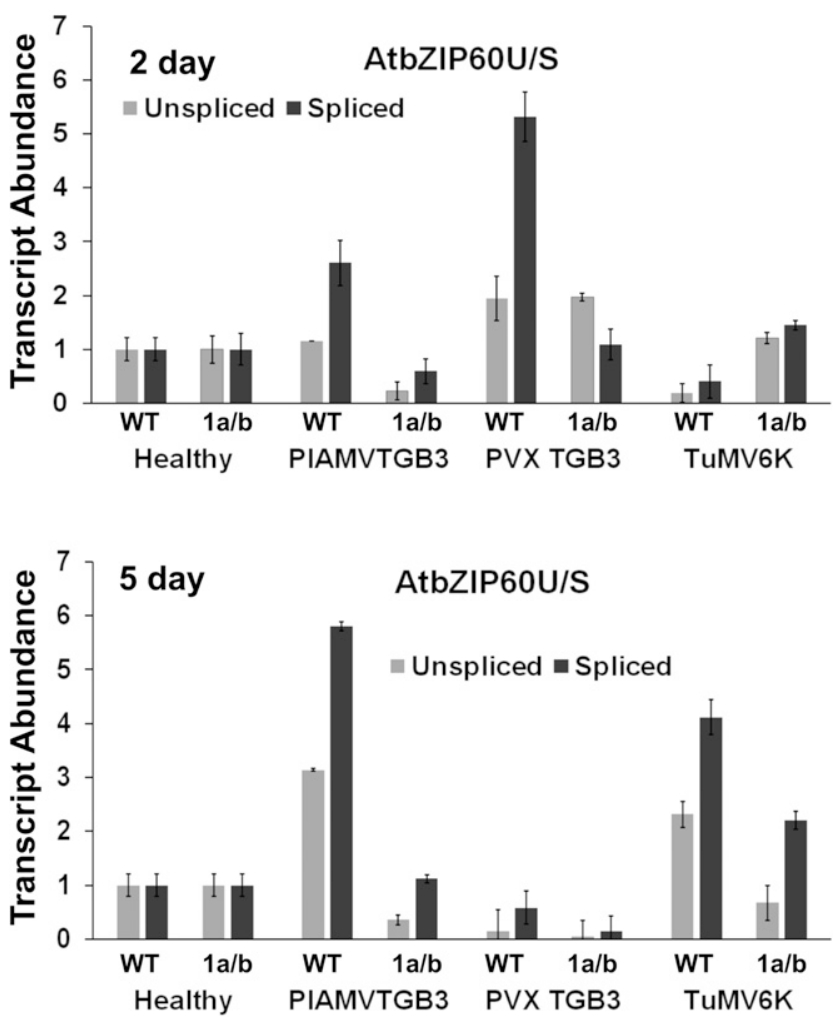

Fig. 2. Splicing of AtbZIP60 transcripts by viral elicitors. A, Boxes illustrate the full-length bZIP60 (bZIP60u) and the shortened bZIP60 (bZIP60s) mRNAs. The illustration highlights the bZIP domain and the putative transmembrane domain (TMD). The line illustration depicts the bZIP60 mRNA and the 23-bp splice fragment that is cleaved by IRE1. The flanking polymerase chain reaction (PCR) primers used for gel-based detection of $b Z I P 60 u$ and bZIP60s transcripts are depicted by arrows. The bZIP60UR is a reverse primer that spans the splice junction, and the intervening sequence is identified in white within the arrow. B, Quantitative reverse transcription (qRT)PCR data shows relative AtbZIP60u and AtbZIP60s transcript abundance at 2 and 5 days postinoculation in the local rosette leaves after infiltration with Turnip mosaic virus (TuMV) 6K2, Potato virus X (PVX) TGB3, and Plantago asiatica mosaic virus (PIAMV) TGB3. Controls included healthy untreated leaves. $U B Q 10$ was used as an internal control for qRT-PCR. Data represent means with standard deviation (SD) of three biological replicates. Data shown are mean \pm SD of three samples within each experiment. In each histogram, asterisks (*) identify shaded bars that were statistically different from the same shaded bars of the control sample treated with agrobacterium alone, demonstrating elicitor-induced gene expression $(P<0.5)$. Statistical analysis was carried out using REST2009 software. 
5.8-fold higher in PlAMV TGB3-treated leaves and approximately fourfold higher in TuMV-treated leaves. For both, AtbZIP6Ou transcripts were two- to threefold above control leaves (Fig. 2B). Interestingly, AtbZIP60s transcripts were reduced in ire1-2/ire 1b-4 mutant Arabidopsis leaves treated with TuMV6K at 5 dpi; compared with wild-type leaves, the level remained above the wild-type control, suggesting the genetic mutations did not completely eliminate IRE1 splicing activity. In combination, these data demonstrate that, for two potyviruses and two potexviruses, the small membrane-binding proteins that reside in the ER activate the IRE1/bZIP60 UPR pathway early in virus infection, as evidenced by enhanced gene expression and bZIP60 mRNA splicing. A second pathway led by AtBI-1 is also induced in parallel.

\section{IREI $a$ and IREIb contribute differently to PIAMV and TuMV infection.}

In response to ER stress, there are three major branch pathways stemming from IRE1, i.e., bZIP60 transcriptional activation, mRNA decay (RIDD), and autophagy (Liu and Howell 2016; Yang et al. 2016). These branch pathways can be separately activated by IRE1a and IRE1b. Therefore, to study the separate contributions of IRE1a and IRE1b to potexvirus and potyvirus infection, wild-type Col-0, irela-2, ire 1b-4, and irela-2/irelb-4 mutant plants were inoculated with PlAMV-GFP $(n=20)$ or TuMV-GFP $(n=18)$. At $10 \mathrm{dpi}, 50 \%$ of wild-type Col-0 plants inoculated with PIAMV-GFP were systemically infected and this rose to $55 \%$ by $12 \mathrm{dpi}$ (Fig. 3A and B). Among ire la- 2 or ire $1 b-4$ mutant plants, 40 to $45 \%$ were systemically infected by $10 \mathrm{dpi}$. At $12 \mathrm{dpi}, 85 \%$ of ire $1 a-2$ plants and $55 \%$ of ire $1 b-4$ were systemically infected. Among the ire 1a-2/ire $1 b-4$ mutant plants, $100 \%$ of the plants were systemically infected by $10 \mathrm{dpi}$ (Fig. 3A and B).

We combined a qualitative analysis of visible systemic infection, monitored by GFP fluorescence in upper noninoculated leaves (Fig. 3A and B) and a quantitative analysis of the leaf area displaying fluorescence intensity, using Image $\mathbf{J}$ software (Fig. 3C). All plants were photographed (Fig. 3A), and the integrated fluorescence density values $(\mathrm{FV})$ for the systemic leaves were collected at 10,12, 17, 19, and $24 \mathrm{dpi}$, were averaged across plants $(n=6)$, and were plotted (Fig. 3C). Analysis of variance (ANOVA) was used to compare the population variances to determine if systemic accumulation of fluorescence was not equal between plant lines (Supplementary Table S2). For PlAMV-GFP, there was greater systemic fluorescence accumulation over time in ire 1a-2 or ire la-2/ire 1b-4 mutant plants than in wild-type Col-0 plants (Fig. 3C) $(\mathrm{FV}>1.0, P<0.05)$. The systemic accumulation of GFP was similar between ire $1 b-4$ and wild type (Fig. 3C) $(\mathrm{FV}<1.0, P>0.1)$. Thus, both in the ire $1 a-2$ and the ire 1a-2/ire 1b-4 mutant plants, PIAMV-GFP systemically infected a higher percentage of plants by $12 \mathrm{dpi}$ and showed higher GFP accumulation in systemic tissue, suggesting a preferential role for IRE1a in systemic movement.

TuMV-GFP infection spread more slowly than PlAMV-GFP and $50 \%$ of wild-type Col-0 plants showed systemic TuMVGFP by 17 dpi (Fig. 3F and G). At 10 dpi, 44\% of the irela-2 plants were systemically infected and $100 \%$ were systemic at 17 dpi. TuMV-GFP spread systemically among $100 \%$ of the ire $1 b-4$ or irela-2/ire $1 b-4$ mutant plants by $10 \mathrm{dpi}$ (Fig. 3F and $\mathrm{G})$. The average FV values for the systemic leaves were collected at 10, 12, 17, 19, and 24 dpi (Fig. 3H). The trend lines and ANOVA indicate that, for TuMV-GFP, there was greater systemic fluorescence accumulation over time in ire $1 b-4$ or ire la-2/ire $1 b$ plants than in wild-type Col-0 plants. Systemic FV accumulation was not different between ire $1 a-2$ mutant and wild-type Col-0 plants. These data suggest that, in the case of TuMV-GFP, IRE1b plays a greater role than IRE1a in systemic virus accumulation (Fig. $3 \mathrm{H}$ ).
Local virus accumulation was examined in the inoculated leaves at 6 dpi, before virus spread systemically. GFP fluorescence was measured in detached leaves $(n=6)$, and the average fluorescent density area was compared between wild-type and mutant leaves (Fig. 3D). PlAMV-GFP was four- to fivefold higher in irela-2 $(P<0.01)$ or irela-2/ire $1 b-4(P<0.001)$ mutant leaves than in control or ire $1 b-4(P>0.1)$ mutant leaves (Fig. 3D). Immunoblot analysis in repeated experiments also indicated that the PlAMV coat protein accumulated to higher levels in irela-2 or ire 1a-2/ire1b-4 mutant leaves than in control or ire $1 b-4$ mutant leaves at $6 \mathrm{dpi}$ (Fig. 3E). With respect to TuMVGFP, the levels of GFP in irela-2, ire 1b-4, and irela-2/ire $1 b-4$ mutant leaves were four- to sixfold greater than in the wildtype Col-0 leaves at 6 dpi (Fig. 3I) but were not significantly different from each other $(P>0.1)$. Immunoblot analysis at $6 \mathrm{dpi}$ revealed that the levels of TuMV coat protein in the irela-2 and ire $1 b-4$ leaves were somewhat greater than in wild-type Col-0 leaves (Fig. 3J) but were significantly higher in the double mutant leaves compared with the wild-type leaves (Fig. 3J).

Combining the analysis of local and systemic virus infection, IRE1a plays a greater role in restricting the overall accumulation of PlAMV-GFP and TuMV-GFP in plants. The preferential local and systemic accumulation of PlAMV-GFP in IREladeficient plants argues that IRE1a plays a greater role in restricting virus systemic movement, but the combined effect of the double mutant also highlights that IRE1b provides a compensatory role in restricting virus. For TuMV-GFP, systemic fluorescence is higher in IRE $1 b$ mutant plants, suggesting that IRE1b may play a greater role in systemic infection with IRE1a playing a compensatory role.

\section{bZIP60 contributes to PIAMV and TuMV infection in Arabidopsis.}

If bZIP60 mRNA splicing is an important downstream activity of IRE1, needed to restrict virus infection, then virus should accumulate earlier in a larger number of bzip60-1 mutant plants (SALK_050203) than in the wild-type Col-0 plants. The bzip60-1 mutant line contains a T-DNA insertion near the start codon of the $b Z I P 60$ mRNA that was previously demonstrated to block accumulation of bZIP60s transcripts (Deng et al. 2011). Of the wild-type plants that were inoculated with PlAMV-GFP $(n=20), 45 \%$ were systemically infected by 10 dpi and $50 \%$ were infected by 12 dpi. Of the bzip60-1 mutant plants $(n=20), 50 \%$ were systemically infected with PlAMVGFP by 10 dpi and $80 \%$ by 12 dpi (Fig. $4 \mathrm{~A}$ and B). The average fluorescence intensity values in the bzip60-1 rosette leaves $(n=6)$ was significantly greater than in wild-type Col-0 plants (Fig. 4C) $(\mathrm{FV}>1.0, P<0.05)$, indicating that loss of bZIP60 lead to systemic increase in virus accumulation. For comparison, we included irela-2/ire $1 b-4$ plants in a statistical analysis of the FV across the population. Statistical analysis comparing the population variance among PlAMV-GFP infected bzip60-1 mutant and irela-2/ire $1 b-4$ mutant indicated that fluorescence accumulation was significantly different among these two lines $(P<0.1)$. At $6 \mathrm{dpi}$, we directly compared the FV values representing PlAMV-GFP accumulation in wild-type, bzip60-1, and irela-2/irelb-4 mutant inoculated leaves. The FV values representing bzip60-1 inoculated leaves were significantly greater than wild-type Col- 0 plants $(P<0.001)$ but not different from ire 1a-2/ire1b-4 infected leaves $(P>0.1)$ (Fig. 4D). Immunoblot analysis demonstrated that the viral coat protein was also elevated in bzip60-1 mutant leaves compared with control leaves at 6 dpi (Fig. 4E).

For TuMV-GFP, $67 \%$ of the bzip60-1 mutant plants were systemically infected at $10 \mathrm{dpi}$ and $100 \%$ were infected at 17 dpi (Fig. 4F and G). The measured FV values in the rosette 
A

PIAMV
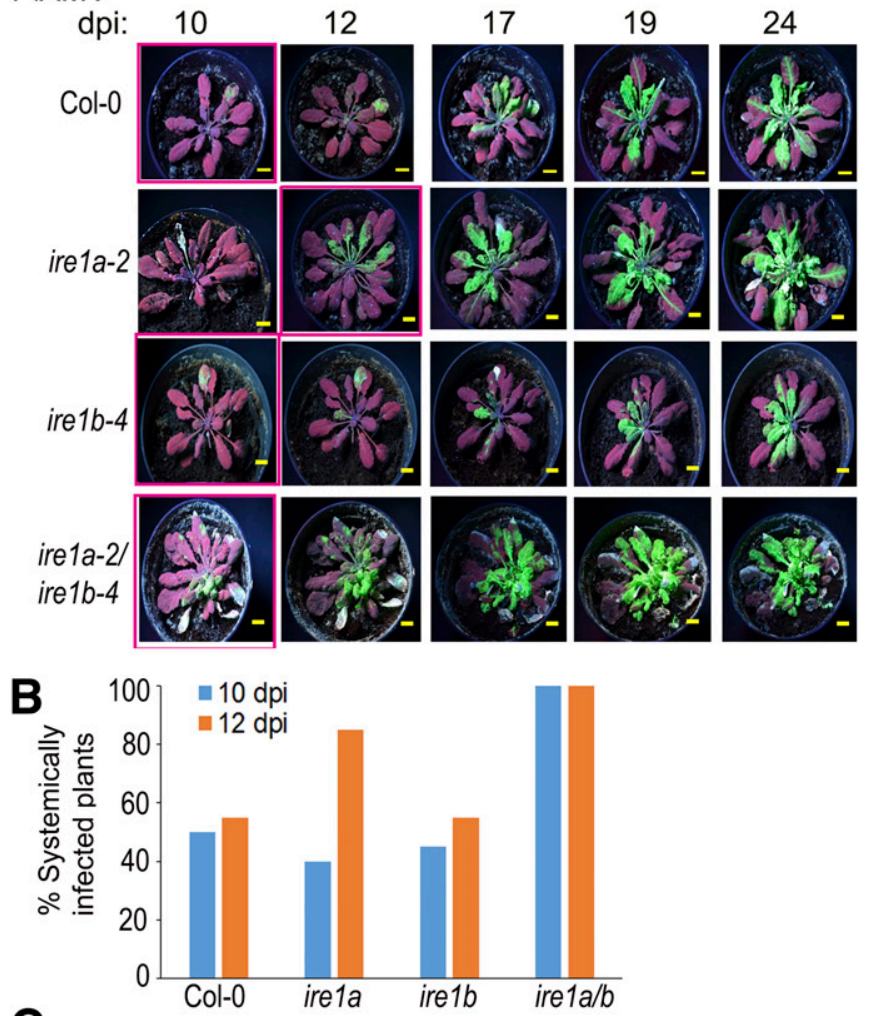

C

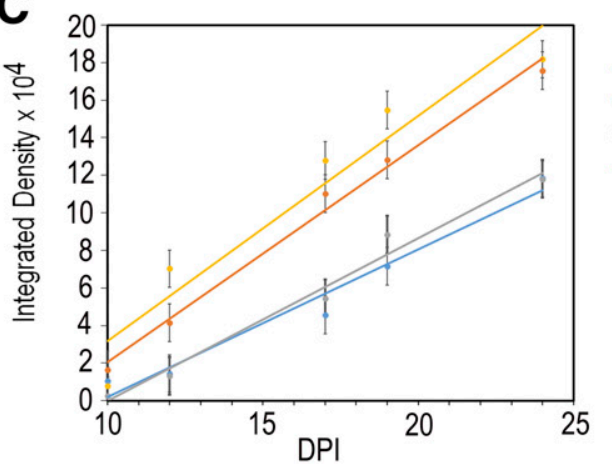

- Col- $0 R^{2}=0.97$

- ire $1 \mathrm{a}-2 \mathrm{R}^{2}=0.99$

- ire $1 b-4 R^{2}=0.98$

- ire $1 a-2 / b-4 R^{2}=0.92$

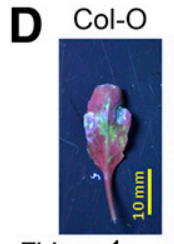

FV: 1

E C
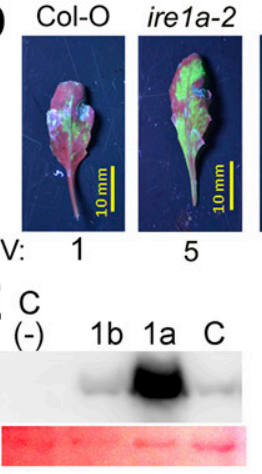

5

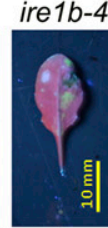

1
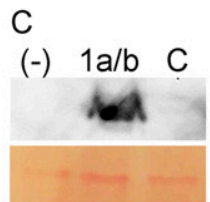

F

TuMV

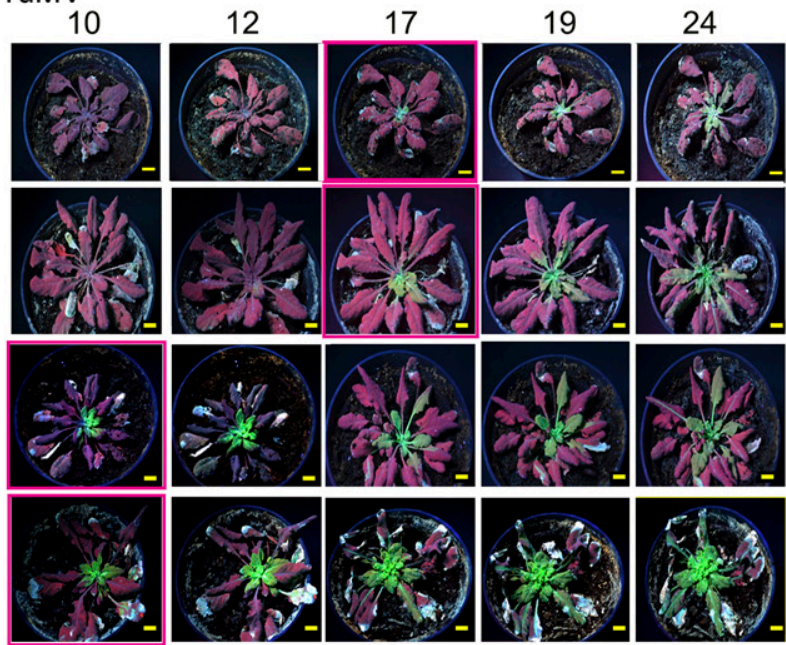

G

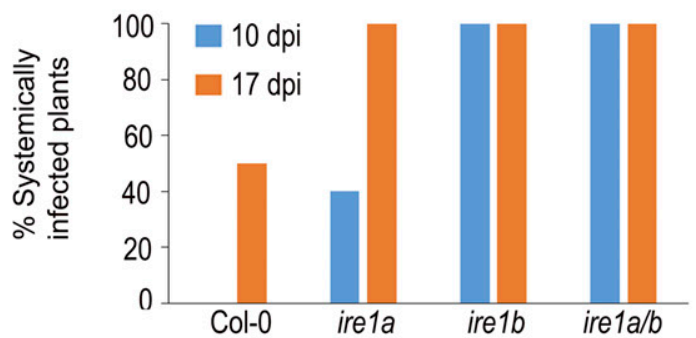

H

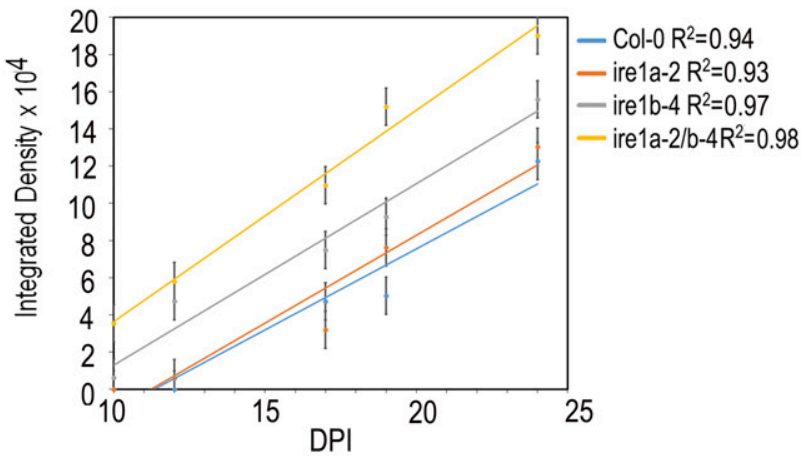

I

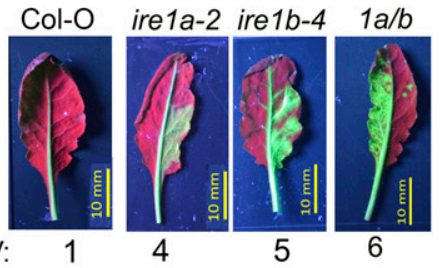

J

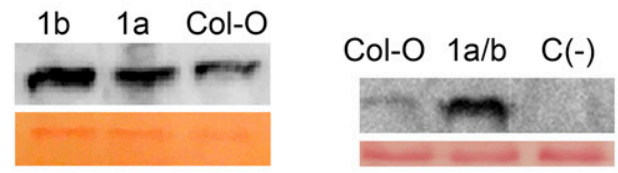

Fig. 3. Systemic Plantago asiatica mosaic virus (PIAMV)-GFP and Turnip mosaic virus (TuMV)-GFP infection in IRE1-defective Arabidopsis plants. A and F, Images of plants infected with PIAMV-GFP or TuMV-GFP taken with a hand-held UV lamp. Days postinoculation are indicated above each column and the wild-type or mutant plant is designated on the left of each row. Red outlines identify the plants in which systemic infection first appeared, which, in some cases, was a small area of a single leaf and in other cases, a broader area. $\mathbf{B}$ and $\mathbf{G}$, The bars indicate the percentage of systemically infected plants at either 10, 12, or 17 days postinoculation (dpi). The percentage values are calculated based on a total population of inoculated plants, which is 20 plants for PlAMV-GFP and 18 plants for TuMV-GFP wild-type or mutant lines. $\mathbf{C}$ and $\mathbf{H}$, Scatter plot values and trend lines represent the average florescence intensity values (FV) of six plants at 10, 12, 17, and 24 dpi, for each wild-type and mutant line inoculated with either virus. D and I, Representative images of inoculated leaves at 6 dpi. For each mutant leaf, the average FV for the entire leaf area was calculated and normalized relative to the average FV for the control leaf. Statistical analysis indicated that the FV for each mutant line was significantly different from wild-type plants $(P<0.05)$. E and $\mathbf{J}$, Immunoblot analysis detecting viral coat protein in inoculated leaves at 6 dpi. Ponceau S-stained gel membrane below the immunoblot shows total protein in each well is constant. Lane $\mathrm{C}(-)$ shows the healthy control and lane $\mathrm{C}$ the wild-type Col-0 inoculated with virus. 
A

PIAMV

dpi:
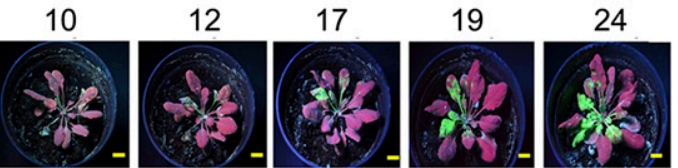

TuMV

Col-0
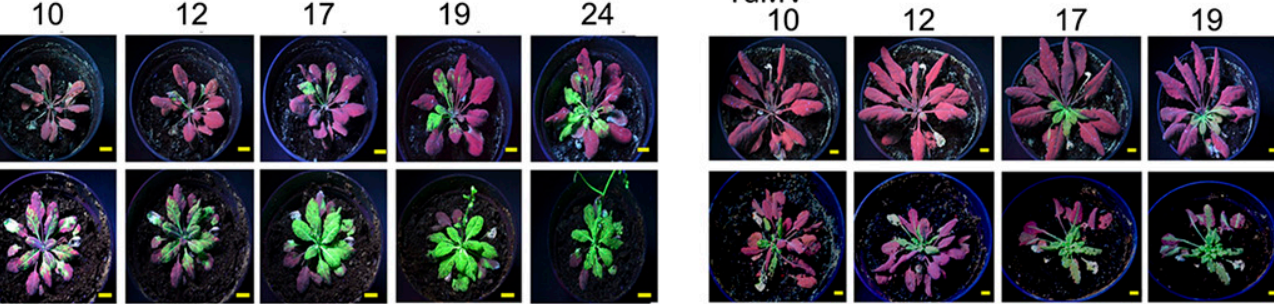

24
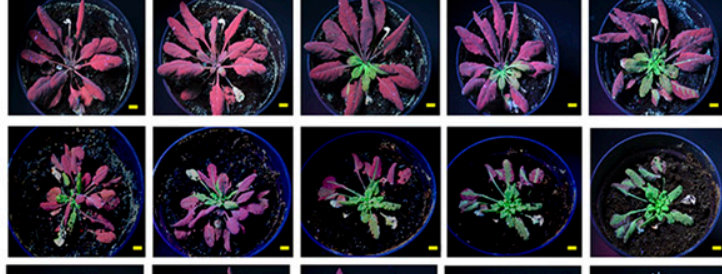

bzip 60
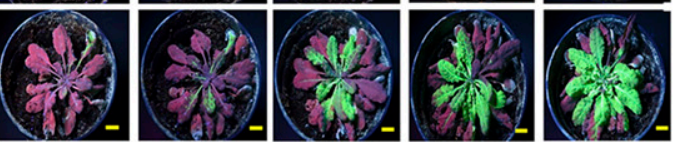

bi1
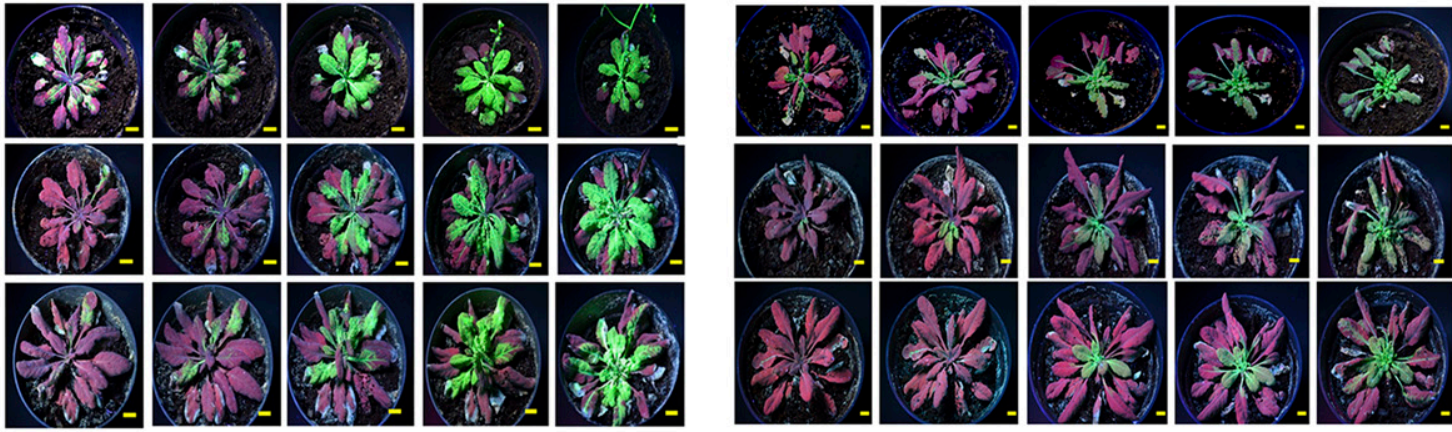

B

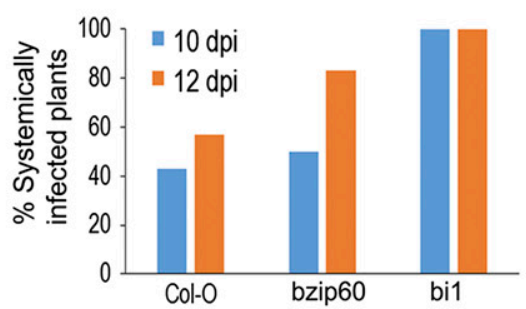

G
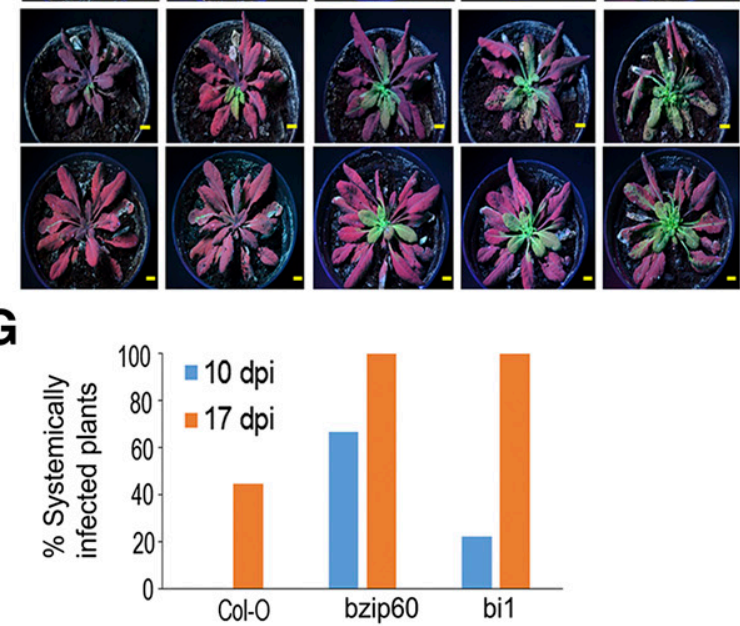

C

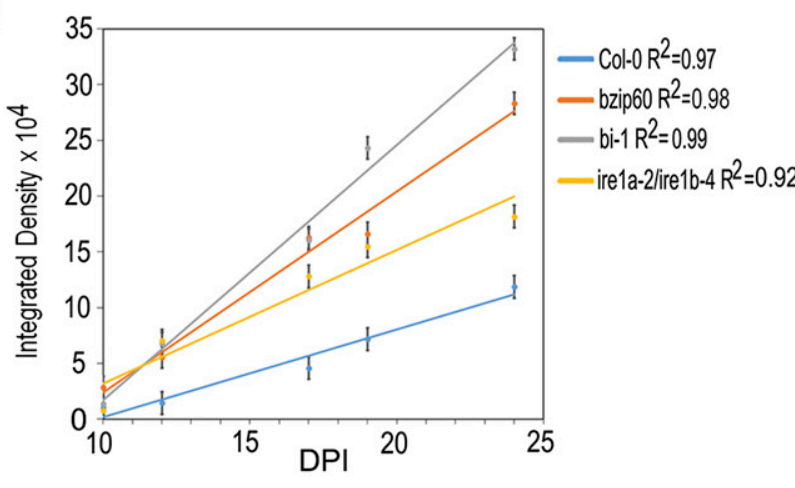

D

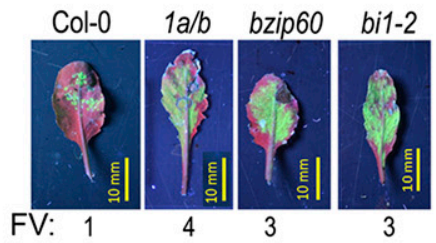

E

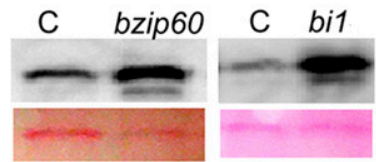

H

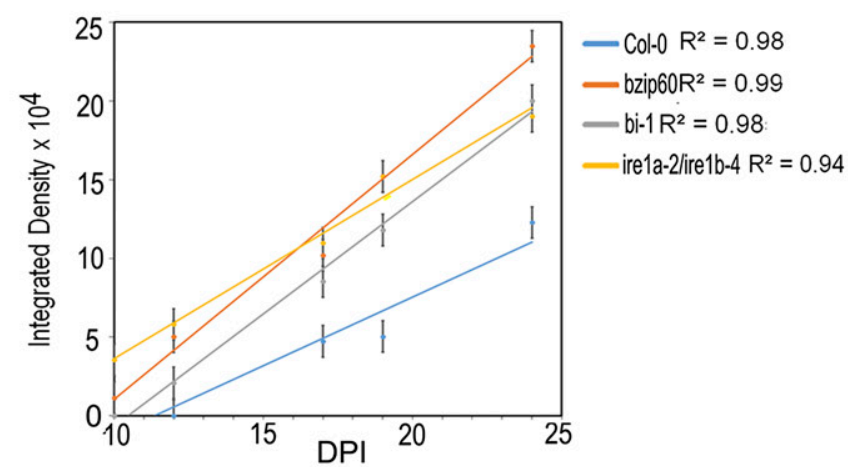

I

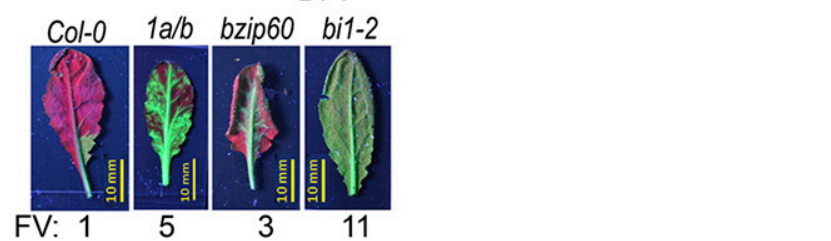

$$
\text { C(-) bi1. C bzip60 }
$$

J

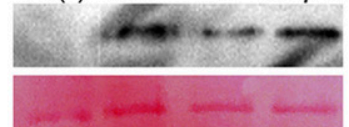

Fig. 4. Systemic Plantago asiatica mosaic virus (PlAMV)-GFP and Turnip mosaic virus (TuMV)-GFP infection in bZIP60-and BI-1-defective Arabidopsis plants. A and F, Images of plants infected with PlAMV-GFP or TuMV-GFP taken with a hand-held UV lamp. B and G, The percentage of PlAMV-GFP or TuMV-GFP systemic plants in a total population was pooled from three experiments and was depicted graphically. The bars indicate the percentage of systemically infected plants at either 10,12, or 17 days postinoculation (dpi). $\mathbf{C}$ and $\mathbf{H}$, Average florescence intensity values (FV) were calculated for three wild-type and mutant plants inoculated with either virus. For PlAMV-GFP- and TuMV-GFP-infected plants, the total average FV for each virus and plant line combination were compared statistically, using analysis of variance and systemic GFP accumulation in bzip60-1, bil-2, and ire 1a-2/ire 1b-4 mutant lines were significantly different from wild-type Col-0 $(P<0.05)$. D and I, Representative images of inoculated leaves at 6 dpi. For each mutant leaf, the average FV for the entire leaf area was calculated and was normalized relative to the average FV for the control leaf. Statistical analysis indicated that the FV for each mutant line was significantly different from wild-type plants $(P<0.05)$. $\mathbf{E}$ and $\mathbf{J}$, Immunoblot analysis detecting viral coat protein in inoculated leaves at 6 dpi. Ponceau S-stained gel membrane below the immunoblot shows total protein in each well is constant. Lane C (-) shows the healthy control and lane C the wildtype Col-0 inoculated with virus. 
leaves were comparable between bzip60-1 and Ire 1-a/Ire1b-4 mutant plants and was greater than in wild-type Col-0 plants over time (Fig. 4H). In the inoculated leaves, TuMV-GFP fluorescence was greater in ire 1 a-2/ire 1b-4 mutant leaves than bzip60-1 mutant leaves $(P<0.05)$. Immunoblot analysis also indicates that the TuMV-GFP coat protein accumulates to a higher level in bzip60-1 mutant leaves than in wild-type Col-0 leaves at 6 dpi (Fig. 4I and J). These combined data further indicate that the IRE1/bZIP60 pathway regulates PlAMV-GFP and TuMVGFP local and systemic infection in Arabidopsis plants.

\section{BI-1 restricts PIAMV and TuMV infection in Arabidopsis.}

To learn whether BI-1 suppresses virus infection alongside the IRE1 machinery, we inoculated homozygous Atbil-2 (CS323793) mutant Arabidopsis plants with PlAMV-GFP or TuMV-GFP. The bil-2 mutant line has a T-DNA insertion near the $5^{\prime}$ end of the gene and does not produce a functional transcript (Watanabe and Lam 2009). In general, the bil-2 mutant plants were more susceptible to PlAMV-GFP and TuMV-GFP than wild-type Arabidopsis plants. PlAMV-GFP spread systemically in $100 \%$ of the bil-2 mutant plants $(n=20)$ by $10 \mathrm{dpi}$ (Fig. 4A, B). For TuMV-GFP, $22 \%$ of bil-2 mutant plants were infected by 10 dpi and $100 \%$ were infected by 17 dpi (Fig. 4G).

The integrated density values for plants between 10 and 24 dpi was quantified and plotted alongside wild-type Col-0, bzip60-1, and ire1a-2/ire1b-4 mutant plants inoculated with PIAMV-GFP or TuMV-GFP for comparison (Fig. 4C and $\mathrm{H}$ ). As for each other mutant line, ANOVA was used to compare the population variances to determine if systemic accumulation of fluorescence was not equal between plant lines. For PlAMVGFP and TuMV-GFP, fluorescence accumulation continued to increase over time in systemic leaves at a level that was greater than in the wild-type leaves (Fig. 4C and H). Statistical ANOVA representing $\mathrm{FV}$ values also confirmed higher virus accumulation in PIAMV-GFP or TuMV-GFP in bil-2 mutant plants than in wild-type Col-0 plants $(P<0.05)$.

The average FV for each virus was also higher in the inoculated leaves at 6 dpi. Examples in Figure 4D and I show fluorescence due to PlAMV-GFP was threefold higher and TuMV-GFP was 11-fold higher in inoculated bil-2 mutant leaves relative to the wild-type leaves. Statistical analysis of detached leaves confirms that eliminating $B I-1$ expression increases virus accumulation $(P<0.01)$. Similarly immunoblot analysis confirmed higher viral coat protein in atbil-2 mutant plants than in wild-type control plants (Fig. $4 \mathrm{E}$ and J). These data indicate that BI-1 also functions to restrict virus local as well as systemic accumulation and, in this experimental context, has similarities with the effects of bZIP60 or IRE1A/B defects.

\section{Homologs of bZIP60 and BI-1 in N. benthamiana and $S$. tuberosum.}

Among metazoans, IRE1 activation leads to unconventional splicing of mRNAs encoding transcription factors such as HACl in yeast, XBP1 in animals, AtbZIP60 in Arabidopsis, and OsbZIP50 in rice (Deng et al. 2011; Duwi Fanata et al. 2013; Gardner et al. 2013; Hirota et al. 2006; Iwawaki and Akai 2006). In the case of AtbZIP60, the unspliced form of the protein cannot be translocated into the nucleus, whereas the spliced form has a frameshift that creates a newly translated region enabling nuclear translocation. In both cases, ER stress induction of genes is severely impacted in plants that are knocked down either by mutation or silencing for expression of AtbZIP60. We previously employed the sequences from AtbZIP60 and other reports of Nicotiana tabacum bZIP60 to design silencing constructs, and the outcome of that research was moderate reduction of $b Z I P 60$ expression. BLAST searches detected sequences in $N$. benthamiana and $S$. tuberosum similar to
AtbZIP60. Allelic differences were not found for Solanum phureja DM1-3 and Solanum chacoense (chc). Alignment of sequences around the mRNA splice site shows that all but one nucleotide is highly conserved among all Arabidopsis, $N$. benthamiana, and potato homologs. These sequences share identity within the 23-nt intron (Fig. 5A). The predicted translation products of the putative full-length bZIP60u protein from $N$. benthamiana, S. phureja DM1-3, and S. chacoense shows similarity with the Arabidopsis bZIP60u product (Fig. 5B). All sequences share a common ZIP domain containing highly conserved basic residues and a leucine-rich region (Fig. 5B). Hydrophobicity estimates predict a single conserved transmembrane domain in the full-length bZIP60u protein in $N$. benthamiana and potato that is downstream of the bZIP domain (Zhang et al. 2015), as reported for AtbZIP60 (Fig. 5C).

The BI-1 protein is also highly conserved among eukaryotes (Chen and Brandizzi 2013b). Using BLAST, we identified sequences in $N$. benthamiana, S. lycopersium, S. phureja DM1-3, and $S$. chacoense (chc). Comparison of the amino acid sequences shows extensive identity among the putative plant BI-1 proteins (Fig. 6A and B). Secondary structure predictions and hydropathy plots indicate that the chcBI-1 and DM1-3 BI-1 proteins have seven transmembrane domains similar to AtBI-1. In $N$. benthamiana, there are five domains that look very much like the AtBI-1 and two domains that show less probability of being transmembrane, based on their hydrophobicity profiles (Fig. 6C).

Based on these analyses of putative $b Z I P 60$ and $B I-1$, we developed qPCR primers for studying $b Z I P 60$ and $B I-1$ induction in elicitor-treated $N$. benthamiana and potato plants. We also developed binary plasmids for gene silencing in $N$. benthamiana and potato, using gene sequences that are highly homologous among these solanaceous genes (Supplementary Fig. S1).

\section{bZIP60 and BI-1 induction in tobacco and potato.}

In $N$. benthamiana plants, two potyvirus 6K2 elicitors (TuMV and PVY) and two potexvirus TGB3 elicitors (from PlAMV and PVX) were delivered by agroinfiltration to $N$. benthamiana leaves. Then, RNA was extracted at 2 and 5 dpi and real time qRT-PCR was used to monitor the accumulation of the putative UPR-related $b Z I P 60$ transcripts and cell death-suppressing BI-1 transcripts (Fig. 7A). We confirmed expression of the viral elicitor mRNA on the leaves by RT-PCR to ensure that changes in host gene expression correlated with expression of the viral proteins in the same tissue. At 2 dpi, NbbZIP60 transcripts were induced by the $6 \mathrm{~K} 2$ or TGB3 proteins by approximately two- to threefold above the control samples (Fig. 7A) and these values generally declined at $5 \mathrm{dpi}$ (data not shown). The NbBI-1 transcripts were sixfold higher in TuMV 6K2-treated leaves, twofold higher in PVY 6K2-treated leaves, and fourfold higher in PVX TGB3-treated leaves than in the agrobacteriumtreated controls at 2 days (Fig. 7A) $(P<0.05)$. We saw no significant change in $B I-1$ expression due to PlAMV TGB3 in $N$. benthamiana $(P>0.05)$.

qRT-PCR was performed using RNA extracted at 2 and 5 days following agrodelivery of PVX TGB3 and PVY 6K2 to $S$. tuberosum leaves (Fig. 7A). For PVX TGB3, the putative StbZIP60 expression was 15 -fold higher at 5 dpi $(P<0.05)$ and putative StBI-1 expression was approximately 10-fold higher at 2 dpi than in control-treated leaves $(P<0.05)$. For PVY 6K2, putative $S t b Z I P 60$ was 34.6-fold higher at 2 dpi and declined to approximately 11.7 -fold at 5 dpi. StBI- 1 was not significantly induced. Following delivery of PVY-GFP or PVX-GFP to $S$. tuberosum leaves, at $2 \mathrm{dpi}$, the putative StbZIP60 transcripts were elevated two- to fourfold, and putative StBI-1 transcripts were elevated approximately fivefold above the control leaves 
(Fig. 7A). In each example, gene induction is an early response to infection, suggesting the host is adapting to the changes in the ER incurred by virus infection.

To determine if bZIP60 and BI-1 function to restrict virus infection in N. benthamiana as in Arabidopsis, we inserted gene fragments into the pHellsgate vector (bzip60si and bilsi) and used agrodelivery to knock down endogenous host transcripts (Fig. 7B). Silencing was verified by semiquantitative RT-PCR conducted at 5 days, using RNA extracted from the infiltrated leaves. The endogenous NbbZIP60 or NbBI-1 transcripts at 35 cycles were reduced 80 to $90 \%$ relative to the control leaves that were treated with agrobacterium alone in repeated experiments $(P<0.05$ by ANOVA). We codelivered the pHells- bzip60si or pHells-bilsi with infectious clones for PVX-GFP or PVY-GFP to $N$. benthamiana leaves and monitored local virus accumulation. By 5 dpi, PVX-GFP fluorescence was greater in the bzip60- and bil-silenced tissue than in leaves that were not treated by silencing (Fig. 7C). In the case of PVY-GFP, we failed to observe GFP in the inoculated leaves, although RT-PCR also confirmed the presence of GFP-containing transcripts. One explanation is that the virus titer is low in the inoculated leaves and, perhaps, virus moves preferentially throughout the mesophyll cells rather than the epidermis.

Total protein extracts from inoculated leaves were separated by sodium dodecyl sulfate-polyacrylamide gel electrophoresis (SDS-PAGE) and were analyzed by immunoblot to detect PVX

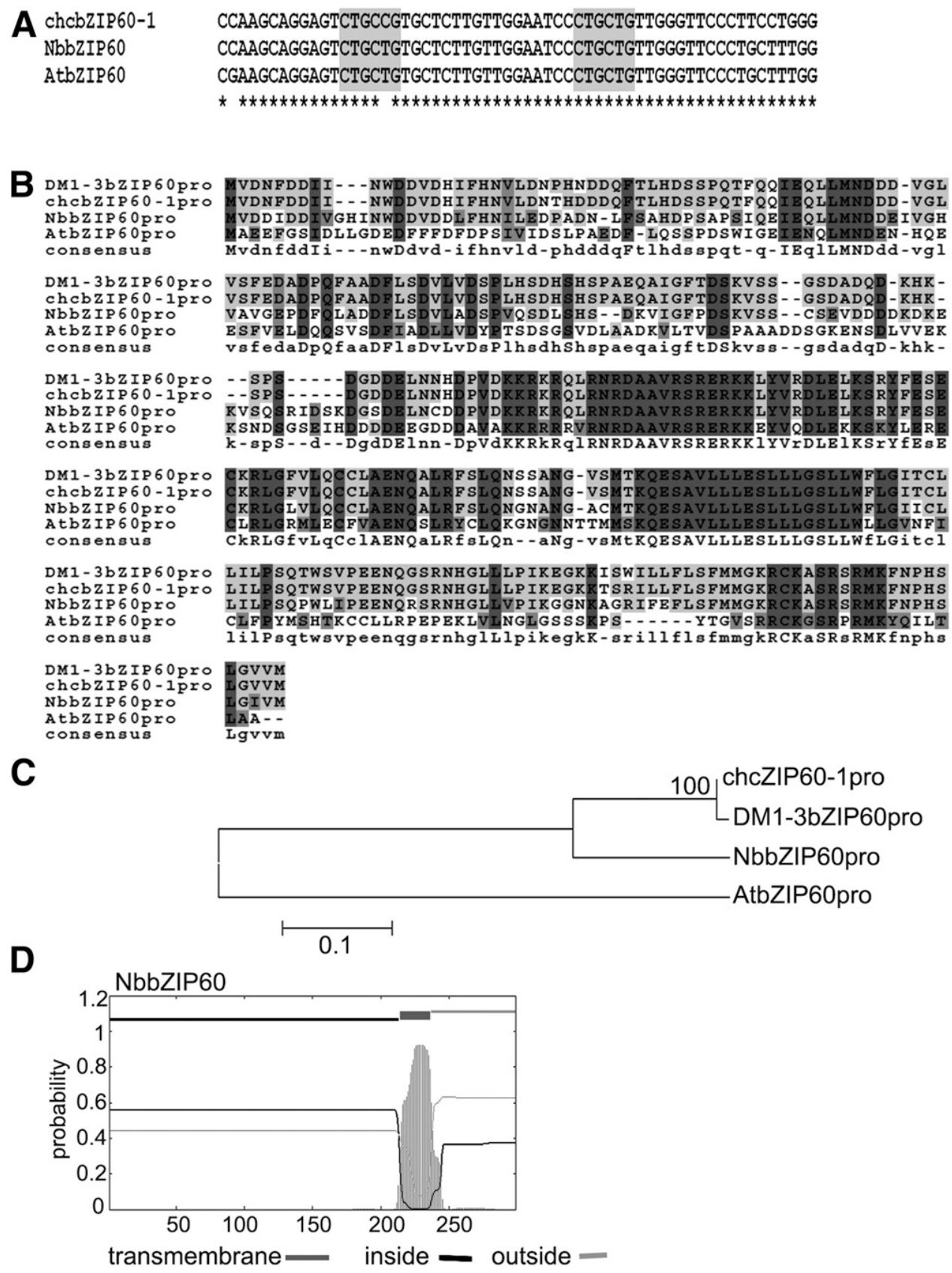

Fig. 5. Comparison of the bZIP60 splice junction and deduced amino acid sequences from Arabidopsis, Nicotiana benthamiana, the reference clone for Solanum phureja DM1-3, and Solanum chacoense (chc). A, Nucleotide sequences surrounding the splice junction. Two conserved splice sites are shaded. B, Amino acid sequence alignments show predicted homologies, using CLUSTALW. Dark and midtone shaded boxes boxes indicate conserved and identical residues. A hyphen indicates the gaps. C, Maximum likelihood tree generated using the full-length bZIP60 protein sequence and MEGA v3.0. D, Hydrophobicity and transmembrane domains were predicted using TMHMM transmembrane prediction in SDSC Biology WorkBench and were confirmed using the SOSUI program. 
or PVY coat protein. In three replicates, the blots showed higher levels of either PVX or PVY coat protein in bzip60- and bil-silenced tissues than in control leaves (Fig. 7D and E). Systemic accumulation of PVY-GFP was confirmed by qRTPCR. The levels of viral RNA were reported relative to the levels of RNA in leaves inoculated with PVY-GFP only (Fig. 7F). In bzip60- and bil-silenced plants, systemic accumulation of PVY-GFP was measured at $16 \mathrm{dpi}$ and was respectively three- and eightfold higher than the level of PVY-GFP in control leaves (Fig. 7F) $(P<0.05)$. These combined data demonstrate that potexvirus and potyvirus accumulation in Arabidopsis as well as in $N$. benthamiana are restricted by the IRE1/bZIP60 pathway as well as the BI-1 cell-death suppressor.
Knockout mutations in IRE1, bZIP60, and BI-1 differentially increase virus-induced necrosis in response to potyvirus and potexvirus infection in Arabidopsis.

We inoculated wild-type and mutant Arabidopsis leaves with TuMV-GFP or PlAMV-GFP (optical density $(\mathrm{OD})=0.5$ ) and monitored the inoculated leaves over 5 days (Fig. 8). Because the leaves are small and close to the soil surface, we carefully infiltrated leaves to minimize inoculation damage. Essentially, wild-type leaves showed some yellowing but no necrosis due to virus infection and this was confirmed by trypan blue. There was no evidence of necrotic local lesions or spreading necrosis along the veins or mosaic/necrosis, which would be the common phenotypes for necrotizing viruses. We noted that ire $1 b-4$,
A

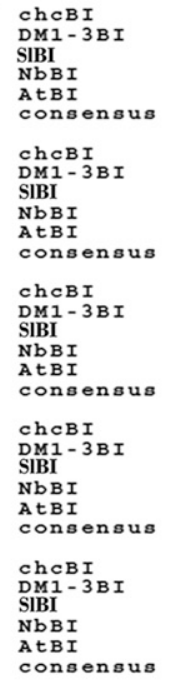

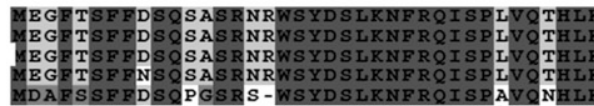
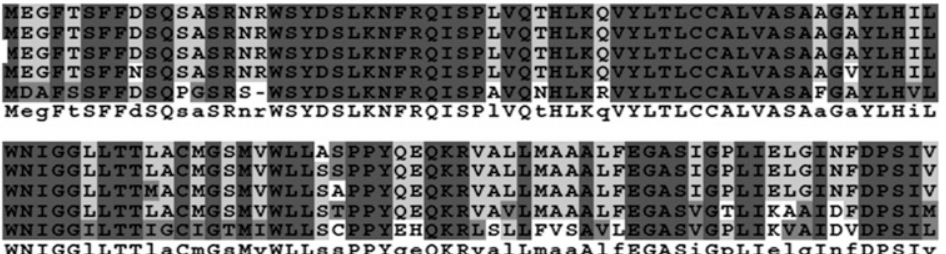

WN I GG ILTT l aCmGs MvWLIs s PPYqeQRRvalLmaaAl EGASiGPLIelgInfDPSIV
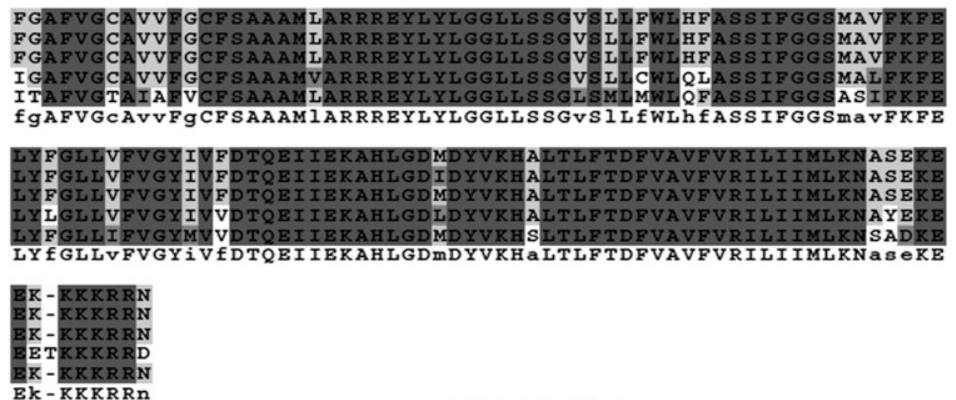

B

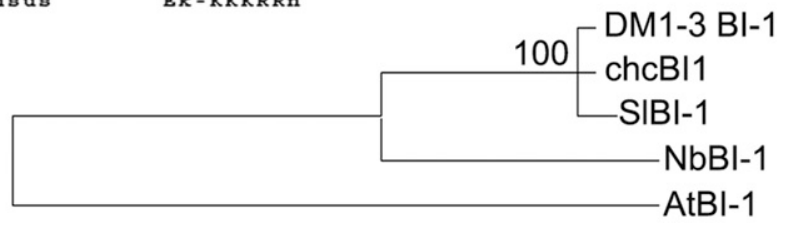

C
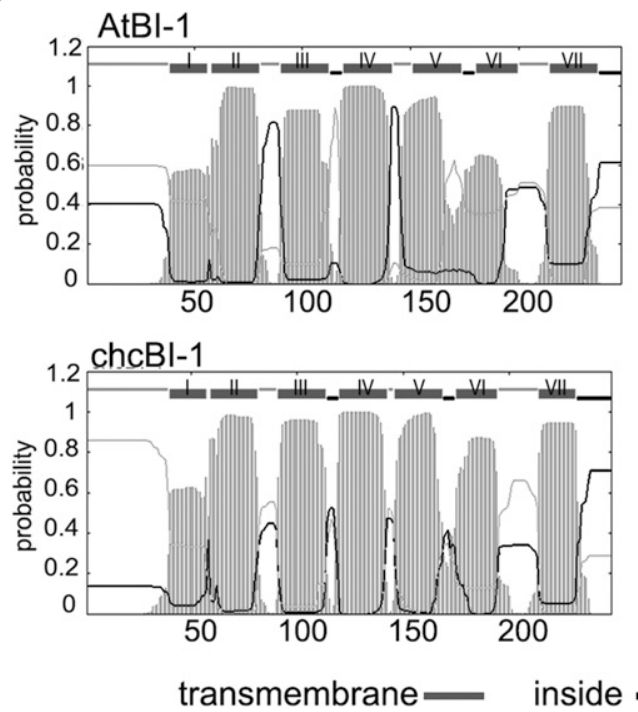

$\mathrm{NbBl}-1$

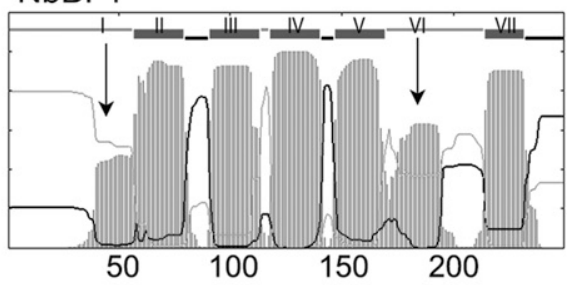

DM1-3BI-1

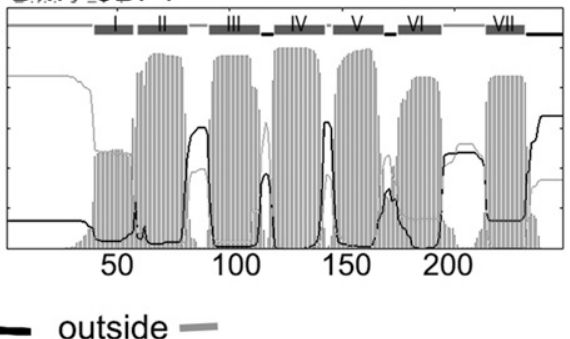

Fig. 6. Comparison of BI-1 deduced amino acid sequences from Arabidopsis, Nicotiana benthamiana, Solanum lycopersicum, the reference clone for Solanum phureja DM1-3, and Solanum chacoense (chc). A, Amino acid sequence alignments show predicted homologies using CLUSTALW. Shaded boxes indicate conserved and identical residues. A hyphen indicates the gaps. B, Maximum likelihood tree generated using the predicted protein sequences and MEGA v3.0. C, Hydrophobicity and transmembrane domains were predicted using TMHMM prediction in SDSC Biology WorkBench and were confirmed using the SOSUI program. 
ire 1a-2/ire1b-4, and bzip60-1 leaves inoculated with either virus showed large necrotic areas confirmed by trypan blue (Fig. 8). For ire 1a-2 mutant plants, necrosis was seen on PlAMV-GFP- but not for TuMV-GFP-inoculated leaves. These outcomes are not surprising, since we consistently have seen differences in the role for IRE1a in PIAMV and TuMV infection. We similarly noted that bil-1 mutant plants were more tolerant to TuMV than PIAMV infection. However, we also noticed that TuMV is often delayed in accumulation relative to PIAMV and we often see GFP in the systemic tissue and less in the inoculated leaves. It is possible that TuMV may move toward the phloem in the inoculated leaves earlier than PIAMV and may escape the inoculated leaf to the upper leaves and may not elicit strong cell death that is acted upon by the BI-1 pathway. This is contrasted by PlAMV, which may spread throughout the primary leaf before moving to the upper leaves. Slow movement of PlAMV out of the inoculated leaf and widespread accumulation in the primary leaf probably enables broad tissue recognition by BI-1 (Fig. 8).

\section{Silencing $b Z I P 60$ and $B I-1$ differentially increases virus-induced necrosis in response to potyvirus and potexvirus infection in $N$. benthamiana.}

To learn if bZIP60 or BI-1 played roles in cell-death regulation involving PVX or PVY, we used agroinfiltration to codeliver PVX-GFP or PVY-GFP with pHells-bzip60si or bHells-bilsi silencing constructs to $N$. benthamiana leaves (Fig. 9A). Among plants inoculated with PVX-GFP, we saw profound chlorosis in bil-silenced leaves at 6 dpi but not in bzip60-silenced or control leaves (Fig. 9A). We did not see any significant changes in PVY-GFP-inoculated leaves.

PVX-GFP spread systemically in all plants by $8 \mathrm{dpi}$, and we continued to monitor plants until 16 dpi to observe fluorescence
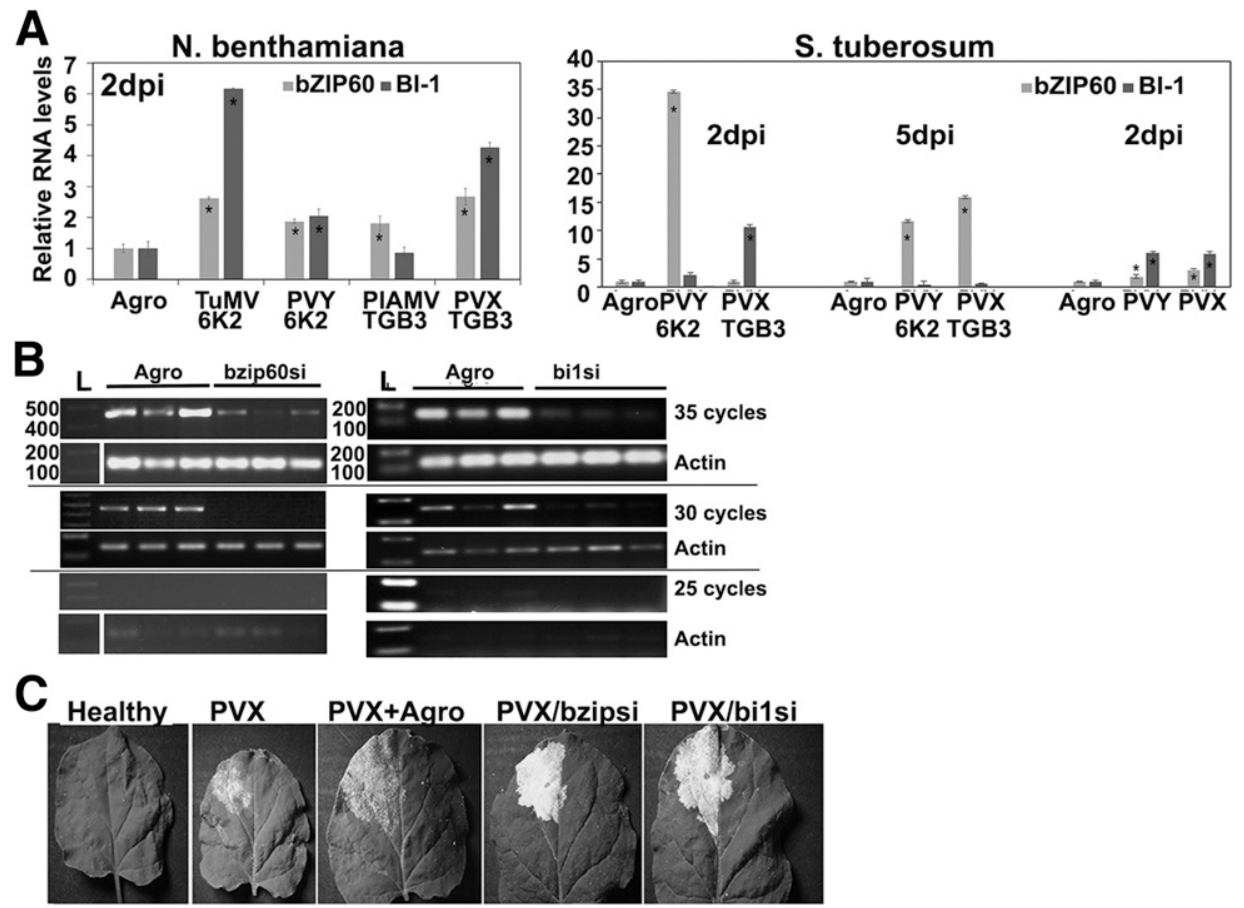

D
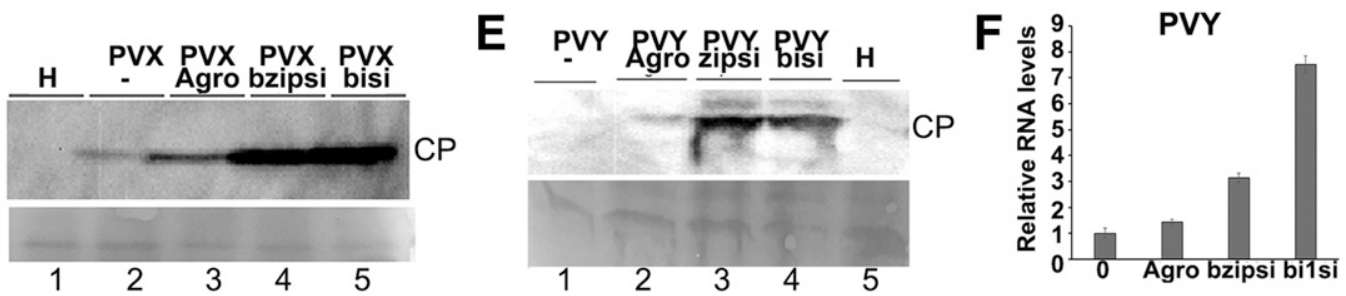

Fig. 7. Potyvirus 6K2 and potexvirus TGB3 elicitors of endoplasmic reticulum stress in Nicotiana benthamiana and Solanum tuberosum. A, Quantitative reverse transcription polymerase chain reaction (qRT-PCR) detecting relative levels of bZIP60 and BI-1 transcripts in N. benthamiana at 2 days postinoculation (dpi) and in $S$. tuberosum at 2 and 5 dpi. $N$. benthamiana leaves were agroinfiltrated, delivering plasmids expressing potyvirus $6 \mathrm{~K} 2$ or potexvirus TGB3 proteins. For Turnip mosaic virus (TuMV) 6K2 and Potato virus X (PVX) TGB3, asterisks (*) identify bars that are significantly different from the control treated with agrobacterium and has $P<0.05$. S. tuberosum leaves were agroinfiltrated to delivery similar plasmids or infectious clones of PVX-GFP or Potato virus $Y$ (PVY)-GFP. Data presented are representative of three independent experiments. Data shown are mean \pm standard deviation of three samples within each experiment. Analysis of variance was used for statistical analysis and indicated that each elicitor or virus induced $b Z I P 60$ and $B I-1$ above the level of the Agrobacterium control treatment $(P<0.05)$. Agroinfiltration treatments were carried out using wild-type Col-0 or mutant IRE1a-2/1b-4 Arabidopsis plants. A, TuMV-GFP or Plantago asiatica mosaic virus (PlAMV)-GFP delivery by agroinfiltration. Control involved using agrobacterium alone. Graphs represent data obtained at 2 dpi. B, Semiquantitative RT-PCR gels shows silencing of bZIP60 and BI-1 in N. benthamiana leaves. Actin II was used as a loading control. Control lanes were treated with agrobacterium and a no-silencing construct, and silenced leaves were infiltrated with agrobacterium carrying pHells-bZIP60 or pHells-BI1. bZIP60 and BI-1 expression were each reduced approximately $90 \%(P<0.05)$. C, Codelivery of silencing constructs and PVX-GFP. Images of detached leaves at 6 dpi show relative levels of fluorescence is higher in silenced leaves than in control leaves. $\mathbf{D}$, Immunoblot analysis of leaves in panel $\mathbf{C}$ treated with PVX coat protein (CP) antisera. Lane 1, control healthy leaf; lane 2, PVX-infected leaf extract; lane 3, mixture of PVX-GFP containing agrobacterium culture and empty agrobacterium culture infiltrated into leaf; lane 4, PVX-GFP in bzip60si-silenced leaf; lane 5, PVX-GFP in bilsi silenced leaf. E, Immunoblot analysis of leaves infected with PVY-GFP. Lane 1, PVY-infected leaf extract; lane 2, mixture of PVY-GFP containing agrobacterium culture and empty agrobacterium culture infiltrated into leaf; lane 3, PVY-GFP in bzip60si-silenced leaf; lane 4, PVY-GFP in bilsi-silenced leaf; lane 5, healthy leaf extract. Ponceau S-stained membrane below gels in panels D and E show equal loading in each lane. F, PVY-GFP accumulation in systemic leaves at 16 dpi was measured using qRT-PCR. 
and symptoms. Images in Figure 9B show GFP fluorescence at 14 dpi. PVX-GFP fluorescence reached all upper leaves, producing a mosaic pattern of disease. In $b i-1-$ silenced plants, GFP fluorescence in the upper leaves was more intense, plants were stunted, and the upper crown of the plant was severely yellowed and necrotic (Fig. 9B and C). These data show that BI-1 provides protection against virus-induced necrosis, unlike bZIP60 in PVX-GFP infected plants. The pattern of responses of bzip60 and $b i$-1-silenced plants to PVX infection resembles the responses seen in bzip60-1 and bil-2 mutant Arabidopsis to PIAMV-GFP.

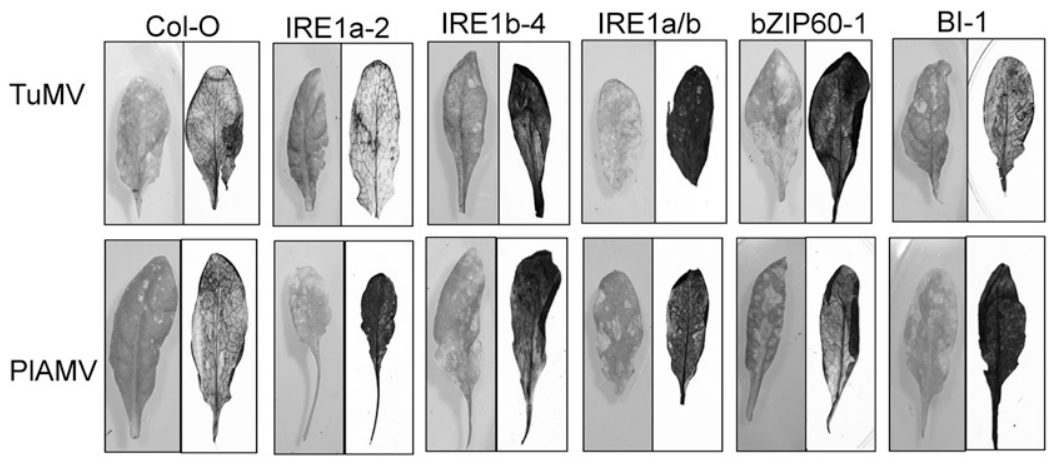

Fig. 8. Images of Turnip mosaic virus (TuMV)-GFP- and Plantago asiatica mosaic virus (PlAMV)-GFP-inoculated Arabidopsis leaves at 6 days postinoculation. Bright field views of detached leaves and the same leaves stained with trypan blue on the right.
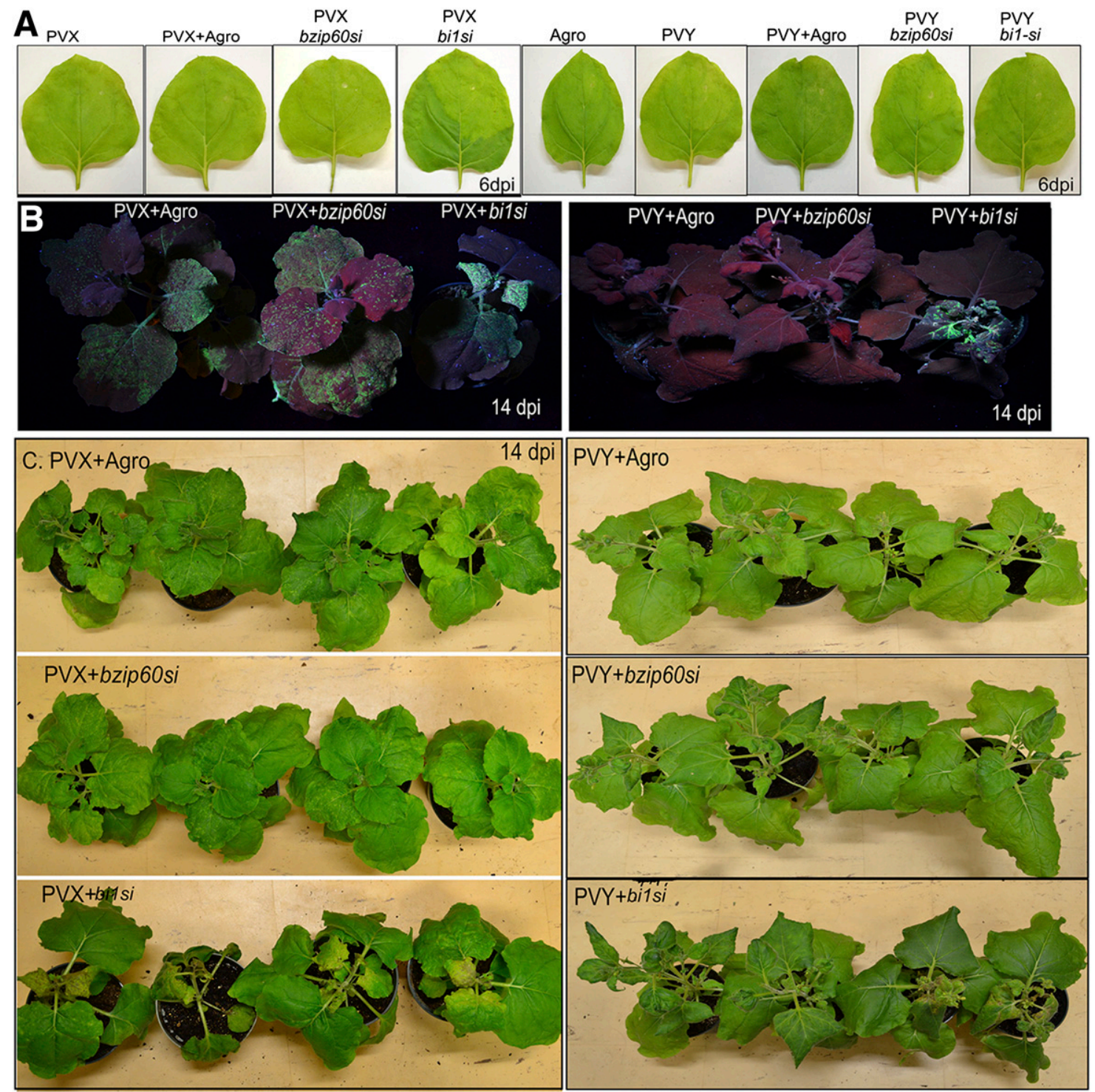

Fig. 9. Images of Potato virus $X$ (PVX)-GFP-and Potato virus $Y$ (PVY)-GFP-infected Nicotiana benthamiana plants. A, Detached infected leaves at 6 days postinoculation (dpi). B, Fluorescence imagines of systemically infected plants at 8 dpi. C, Images of infected wild-type and bzip60si- or bi-1si-silenced plants at 14 dpi. 
PVY-GFP spread systemically and fluorescence took longer to observe. Plants showed obvious symptoms and tested positive for PVY-GFP by RT-PCR. At $14 \mathrm{dpi}$, fluorescence was obvious only in the upper leaves of bi-1-silenced plants (Fig. 9B and $\mathrm{C}$ ). The pattern of mosaic disease in control and bzip60silenced plants was similar, but bi-1-silenced plants showed severe necrosis and stunting. In fact, the pattern of PVY-GFP fluorescence followed the spreading necrosis in the upper leaves. Careful examination of the plants in Figure 7C showed that necrosis in bil-silenced leaves infected with PVY-GFP or PVX-GFP begins at the petiole and the base of the leaf and moves outward, following the classic pattern of virus unloading into sink tissue. Thus, for both potyvirus and potexviruses, BI-1 provides protection from systemic necrosis.

\section{DISCUSSION}

Mutations in IRE1a, IRE1b, and bZIP60 in Arabidopsis and silencing bZIP60 in $N$. benthamiana plants was employed to demonstrate that these genes act to restrict infecting potexviruses and potyviruses. These data also revealed that activation of IRE1 and bZIP60 is a broadly conserved function of the potexvirus and potyvirus TGB 3 and $6 \mathrm{~K} 2$ proteins. With respect to virus infection, the data presented in this study supports the notion that IREI $a$ and IREIb overlap in their ability to respond ER stress but, also, suggests that there may be differences with regard to which isoform is dominant in regulation of potexvirus and potyvirus infection. First, the ire la-2 mutation led to a much greater accumulation of PlAMV (as represented by GFP and coat protein levels) than the ire $1 b-4$ mutation in local and systemic leaves, arguing that IRE Ia plays a greater role in PlAMV TGB3 recognition.

Second, the ire $1 a-2$ and ire $1 b-4$ mutations equally altered the accumulation of TuMV in the inoculated leaves. The proportion of ire $1 b-4$ mutant plants systemically infected with TuMV-GFP was uniquely higher than in wild-type plants at $10 \mathrm{dpi}$, suggesting that $I R E I b$ has a unique role in systemic infection. These data contrast published reports using tunicamycin or heat to elicit ER stress, in which IRE1a and IRE1b typically compensate for loss of the related isoform (Chen and Brandizzi 2012; Deng et al. 2011).

Viral elicitors were shown to induce unconventional bZIP60 mRNA splicing through interactions with IRE1a/b. The levels of bZIP60s transcripts were reduced in irela-2/ire $1 b-4$ mutant plants compared with wild-type inoculated plants. The ratio of spliced to unspliced AtZIP60 transcripts was temporally increased in wild-type plants transfected with PVX TGBp3 at $2 \mathrm{dpi}$, followed by a decline in levels at $5 \mathrm{dpi}$. This tendency is somewhat different from that of PlAMV TGBp3 and TuMV $6 \mathrm{~K} 2$. It is important to point out that, on occasion, the $b Z I P 60 u$ transcripts in ire 1a-2/ire $1 b-4$ mutant plants was elevated above the control agrobacterium-treated plants (Figs. 1A and 2B) although suppressed relative to the wild-type plants treated with either TGB3 elicitor, and this pattern of expression was not seen in leaves treated with the potyvirus $6 \mathrm{~K} 2$ elicitors. One explanation is that more than one ER sensor was activated by the viral protein. There are examples, using abiotic stressors, in which two ER stress sensors are activated and appear to act on the same pathways. In particular, the IRE1 and bZIP28 membrane-associated proteins are both activated by ER stress agents such as tunicamycin and dithiothreitol. Another ER stress sensor or transducer is bZIP17, which is activated by salt stress in a manner that is related to abscisic acid signaling (Liu and Howell 2016; Liu et al. 2008). Activation of IRE1 is reported to involve direct interactions with misfolded proteins in the ER, while bZIP28 and bZIP17 activation involves indirect activation involving the ER chaperone BiP (Srivastava et al. 2013). These
UPR transcription factors, bZIP60s, bZIP28, and bZIP17, recognize promoters that contain ER stress responsive cis-element I (ERSE-I) or the plant-unfolded protein response element (P-UPRE) (Henriquez-Valencia et al. 2015). While ER stress tolerance may be reduced by mutations in IREI affecting $b Z I P 60$ mRNA splicing, conditions may exist for indirect activation of bZIP28 or bZIP17 (Henriquez-Valencia et al. 2015; Liu and Howell 2016; Srivastava et al. 2013). Evidence shows that bZIP60 transcripts are reduced in ire 1a-2/ire $1 b-4$ mutant plants compared with the wild-type plants treated with the same viral elicitors but remain above the levels for bZIP60 transcripts in control-treated plants. This argues that bZIP28 or bZIP17 may provide a compensatory role in gene induction, following agrodelivery of either potexvirus TGB3.

With regard to the role of $b Z I P 60$ in virus infection, the proportion of PlAMV-GFP or TuMV-GFP in systemically infected bzip60-1 mutant Arabidopsis plants was higher than wildtype plants at 12 and $17 \mathrm{dpi}$. In addition, the expression of $b Z I P 60$ mRNA was induced in Arabidopsis, N. benthamiana, and in S. tuberosum following potyvirus (TuMV and PVY) or potexvirus (PIAMV and PVX) infection or following A. tumefaciens delivery of the respective 6K2 or TGB3 genes (Ye and Verchot 2011; Ye et al. 2011, 2013; Zhang et al. 2015). This report demonstrates that PVX TGB3 requires IRE1a/b to mediate bZIP60 induction, complementing prior work that revealed that TGB3association with the ER is also essential to induce bZIP60 expression. (Ye et al. 2011, 2013). In another study, TuMV 6K2 was identified as a factor that can induce bZIP60 mRNA splicing in a manner that was dependent upon IRE1 but did not require direct interacts between TuMV $6 \mathrm{~K} 2$ and IRE1a or IRE1b (Zhang et al. 2015). The tendency for rapid increase in bZIP60 transcript levels differs according to the identity of the viral elicitor in side-by-side experiments. In Arabidopsis, PVX TGB3 evoked higher bZIP60 transcript levels at 2 and $5 \mathrm{dpi}$, whereas PlAMV TGB3 or TuMV 6K2 delivery produced higher levels at 5 dpi. In N. benthamiana, bZIP60 transcripts were higher at 2 days postinfiltration following agrodelivery each viral elicitor. It was surprising to note that $S$. tuberosum was more sensitive and responsive to these viral elicitors. PVX TGB3 and PVY 6K2, respectively, elicited approximately $15-$ and $>30$-fold increases in bZIP60 transcripts, greater than control leaves treated with only agrobacterium.

The mechanism for recognition of the viral TGB3 and 6K2 proteins may not be equivalent, considering the different elicitorinduced patterns of $b Z I P 60$ transcript abundance at 2 and 5 dpi. Considering a model in which IRE1 activation is by direct binding to an elicitor or unfolded protein, these data argue that the TGB3 and $6 \mathrm{~K} 2$ proteins either recognize different binding sites on IRE1 or that they interact with one or more unidentified IRE1-related cofactors. The mechanism of IRE1 activation in plants is not known; however, activation in yeast involves dissociation of BIP from the ER luminal arm of IRE1, followed by IRE1 dimerization (Sano and Reed 2013). While these data confirm a role for an IRE1/bZIP60 pathway in restricting local and systemic accumulation of potexvirus and potyvirus infection, further investigation is needed to elucidate the mechanism for $6 \mathrm{~K} 2$ or TGB3 activation of the IRE1/bZIP60 ER stresstolerance pathway.

$B I-1$ is a known regulator of ER stress-mediated cell death in plants and apoptosis in mammals. In mammals, $B I-1$ binds to Bax and blocks the activity of IRE1-mediated cell death, whereas the action of BI-1 that modulates cell fate in plants is not known (Chae et al. 2004; Kawai-Yamada et al. 2004). This is because a plant homolog for Bax has not been identified and direct interactions between BI-1 and IRE1 have not been demonstrated in plants. In Arabidopsis, $N$. benthamiana, and $S$. tuberosum, BI-1 expression was induced alongside $b Z I P 60$ 
and, in some cases, expression seemed to be hampered in the ire 1a-2/ire1b-4 mutant plants. While the data were not sufficient to suggest that $B I-1$ expression was directly linked to IRE1, there is a strong indication that the same viral elicitors that activate the IRE1/bZIP60 pathway can independently activate $B I-1$ expression.

We report that BI-1, regardless of its role in cell fate regulation, plays a direct role in restricting virus accumulation locally and systemically. Knockdown of BI- 1 through mutagenesis or gene silencing led to an increase in virus accumulation in Arabidopsis and N. benthamiana plants. In mammalian cells, Bax and Bak are directly involved in influenza A virus replication, but reports typically suggest that increases in virus replication are the result in BI-1 suppression of cellular caspases and apoptotic cell death. Notably in the case of influenza, knockdown of Bax in the presence of influenza A leads to an increase in autophagy (McLean et al. 2009). In mammalian cell culture, $B I-1$ deficiency is associated with accumulation of autophagosomes and lysosomal activity as the result of imposed ER stress (Castillo et al. 2011). While the target of $B I-1$ in plants is not known, it is worth considering that knockdown of $B I-I$ in plants could alter the pattern of autophagy and this may, in turn, regulate virus accumulation.

These data involving BI-1 provide further linkage between the role of ER stress and cell fate regulation with respect to plant-virus infection. In a related study comparing PVX-GFPand TMV-GFP-infected $N$. benthamiana plants, we reported that $\mathrm{BiP}$ expression may be important to negatively regulate cell death during potexvirus infection (Ye et al. 2013). In a set of experiments, PVX-GFP-infected plants showed necrotic flecks on the upper leaves, coinciding with elevated transcripts of bZIP60 and BiP. Coinfection of PVX and TMV showed severe systemic necrosis coinciding with suppressed levels of bZIP60 and BiP. These data led us to consider that certain viruses, such as PVX (but not TMV), may use ER stress machinery to limit cell death during virus infection. In this current study, necrosis was evident in virus-inoculated Arabidopsis leaves that were deficient in IRE1 or bZIP60 expression, although necrosis did not spread systemically. In bzip60si- silenced $N$. benthamiana plants, we did not observe necrosis in the inoculated leaves and plants showed characteristic mosaic symptoms in the systemic leaves, indicating that the IRE1/bZIP60 pathway is not directly responsible for appearance of systemic necrosis. However, the bil-si silenced $N$. benthamiana plants showed systemic necrosis following PVX or PVY infection and virus titers were higher in systemic tissues, as seen by GFP expression or qRT-PCR. The infected bil-si-silenced plants were stunted, and the levels of GFP in the systemic leaves was noticeably higher in comparison with the control plants. In another study using $N$. benthamiana, the helicase domain of PlAMV RdRp was the determinant of cell death by PlAMV infection (Komatsu et al. 2010). Mutational analysis and expression of the viral RdRp outside the context of the virus genome by agrobacterium infiltration indicated that overexpression of the viral RdRp or higher levels of protein accumulation during infection can elicit necrosis (Komatsu et al. 2011). Similarly for Alternaria mosaic virus (AltMV), another potexvirus, accumulation of the viral RdRp was a major contributor to leaf necrosis (Lim et al. 2010). For potexviruses, in general, it is not clear if cell death is regulated by an elicitor activity of the viral $\mathrm{RdRp}$ or if it is the ability of this $\mathrm{RdRp}$ protein to control amplification of viral transcripts encoding the viral TGB3 elicitor (Komatsu et al. 2010, 2011). In combination, these observations suggest that restricting virus multiplication should limit systemic necrosis.

Loss of BI-1 resulted in a spreading systemic necrosis following potexvirus or potyvirus infection. This is the second report from our group showing the potexvirus TGB3 protein triggers PCD (Ye et al. 2013). TGB3-induced cell death is dependent upon the SKP1 protein, which is a component of the SCF ubiquitin-ligase system (Chang et al. 2009; Hermand 2006; Hong et al. 2013). Although the mechanism for BI-1mediated cell-death protection in plants is not clear (KawaiYamada et al. 2004), these combined data support a model in which the ubiquitin ligase machinery and BI-1 coordinate to regulate $\mathrm{PCD}$ during plant-virus infection. Tobacco plants overexpressing mammalian $\mathrm{Bcl}-\mathrm{xl}$ also showed TGB3-triggered PCD. Bcl-xl is a mammalian antiapoptotic protein that interacts with BI-1 (Chen et al. 2003; Khanna et al. 2007; Paul et al. 2011; Ye et al. 2013; Xu et al. 2004). In mammalian cells, BI-1 provides protection in response to ER stress, altered intracellular $\mathrm{Ca}^{+2}$ homeostasis, or reactive oxygen speciesmediated cell death (Castillo et al. 2011; Chae et al. 2004; Ishikawa et al. 2013; Janssen et al. 2009; Kang and Reynolds 2009).

Data presented in this study suggest that BI-1 also plays a role in regulating virus titer alongside its role mediating resistance to cell death. One explanation is that BI-1 moderates host susceptibility to virus infection. BI-1 has been shown to play a role in barley susceptibility to the biotroph Ustilago maydis (Hof et al. 2014). The Pep1 effector of $U$. maydis is a peroxidase inhibitor that suppresses PAMP-triggered oxidative burst by targeting extracellular peroxidases (Hemetsberger et al. 2015). Deletion of Pepl provokes a hypersensitive response that can be suppressed by $B I-1$ overexpression. The hallmarks of cell death in this system include induction of caspase-3 like activities and autophagy (Hof et al. 2014). Considering this model of fungal biotrophic interactions, it is possible that successful biotrophic virus-host interactions require suppression of cell death, mediated by the proteasome and BI-1 machineries. While fungal pathogens target extracellular peroxidases for inhibition, plant viruses may target peroxidases for degradation within the cell, prior to their export into the apoplast. A model in which the proteasome is degrading a prodeath factor that monitors cellular $\mathrm{Ca}^{+2}$ stores, oxidative stress, caspase-3 like activities, or autophagy at the same time that BI-1 is induced by virus infection to provide further protection against PCD is reasonable. It is possible that, PCD-inhibiting functions that play a role in biotrophic fungal interactions also play a role in mediating biotrophic virus infections. While this study did not elaborate whether BI-1dependent necrotic death is related to the SKP1-dependent death described previously, these combined studies indicate that cell death regulation is a necessary component of biotrophic virus infection.

\section{MATERIALS AND METHODS}

\section{Plasmids, bacterial strains, and plant materials.}

pGR208 is a binary vector containing the PVX-GFP genome and is deliverable to plants by agroinfiltration (obtained from P. Moffett). GFP-tagged infectious clones of TuMV, PLAMV, and PVY were constructed in binary vectors that enable efficient infection using agroinfiltration. PVY 6K2, TuMV 6K2, PVX TGB3, and PlAMV TGB3 genes were inserted into the pMDC32 binary plasmids for efficient agroinfiltration. The PVY-GFP infectious clone was prepared using the N605 infectious clone with introns and contains a GFP-coding region between NIb and coat protein-coding regions as described previously (Vassilakos et al. 2016).

Genomic sequences corresponding to $B I$ and bZIP60 were amplified from PVY-resistant $S$. chacoense clone 39-7 genomic DNA. One unique BI gene sequence and two bZIP60 sequences were isolated. The two bZIP60 sequences were $99.99 \%$ 
identical at the nucleotide level (17 nt differences out of 2,124 nt). Genomic sequences were submitted to GenBank: chcBI, accession number KX459425; chcbZIP60a, number KX459426; chcbZIP60b, number KX459427. For silencing in $N$. benthamiana and $S$. tuberosum, BI and bZIP60 gene regions were PCRamplified from clone 39-7 genomic DNA. The 804-bp (BI) and 633-bp (bZIP60) products of PCR were digested with SalI and $X b a \mathrm{I}$ restriction endonucleases and were ligated into the same sites in the pENTR-1A vector (ThermoFisher), followed by verification by sequencing using vector-specific primers. Inserts were transferred to pHellsgate, using LR clonase (ThemoFisher) according to the manufacturer's instructions. Proper insertion of bZIP60 and BI fragments was verified by sequencing. All plasmids were maintained in Agrobacterium sp. strain GV3101.

Arabidopsis thaliana ecotype Col-0 and independent homozygous transfer DNA (T-DNA) insertion lines of bZIP60-2 (SAIL_283_B03) and BII-2 (CS323793; locus At5G47120) were obtained from the Arabidopsis Resource Center (Ohio State University). We obtained homozygous T-DNA insertion lines IRE1a-2 (SALK_018112), IREIb-4 (SAIL_238_F07), IRE1a-2/1b-4, bZIP60-1 (SALK_050203; locus At1g42990) from K. Pajerowksa-Mukhtar (Departent of Biology, University of Alabama). Genotyping primers used to confirm homozygous lines containing the T-DNA insertion in the gene of interest were reported by Zhang et al. (2015) and Watanabe and Lam (2006). Arabidopsis, Nicotiana benthamiana, and Solanum tuberosum cultivar Katahdin were grown in chambers with 16-h light and 8-h dark conditions at $23^{\circ} \mathrm{C}$. S. tuberosum plants were micropropagated in Murashige Skoog media with $0.8 \%$ agar and were then rooted in soil, with high humidity, for several days and were slowly transferred to normal growthchamber conditions for 3 weeks.

\section{RT-PCR and bZIP60 splicing assay.}

Primers used in the study for RT-PCR were reported previously (Moreno et al. 2012; Ye et al. 2011; Zhang et al. 2015). For qPCR detection of $B I-1$, we utilized forward and reverse primers. For gel-based bZIP60 splicing assays, we employed primers that amplify both the unspliced and spliced forms of bZIP60 that were previously reported (Parra-Rojas et al. 2015).

Arabidopsis, $N$. benthamiana, and $S$. tuberosum leaves were infiltrated with agrobacterium and, then, leaf punches were harvested at 2 or 5 dpi into liquid nitrogen. RNA was extracted using the Maxwell LEV simplyRNA purification kit (Promega). ThermoFisher high-capacity cDNA reverse transcription kit (ThermoFisher) and random primers were employed for cDNA synthesis. Efficiencies of all primers were verified by normal RT-PCR and gel electrophoresis. For the qPCR-based assay, transcript abundance was quantified using Power SYBR Green II PCR master mix (ThermoFisher) in the ABI 7500 PCR machine (ThermoFisher) or using Kleengreen PCR master mix (IBI Scientific) and the Light Cycler 96 system (Roche). Reactions were incubated, first, at $95^{\circ} \mathrm{C}$ for $10 \mathrm{~min}$ and then for 40 cycles of $95^{\circ} \mathrm{C}$ for $15 \mathrm{~s}$ and $60^{\circ} \mathrm{C}$ for $60 \mathrm{~s}$. Since $b Z I P 60$ is activated by $\mathrm{Tm}$ treatment or salicylic acid (SA), we calculated the fold induction of bZIP60 following treatment with $5 \mu \mathrm{g}$ of Tm per milliliter or $0.5 \mathrm{mM} \mathrm{SA}$ at $0,2,4$, and $8 \mathrm{~h}$. The relative increase of $b Z I P 60$ and $B I-1$ transcripts was calculated using the comparative cycle threshold $\left(\mathrm{C}_{\mathrm{T}}\right)$ method, which employs the equation $2^{\text {-ddCT }}$, where the value for the endogenous control and calibrator (healthy control) are subtracted from the target sample to provide the $\mathrm{ddC}_{\mathrm{T}}$ value. The endogenous control for Arabidopsis was ubiquitin-10 (UBI-10) and, for $N$. benthamiana and $S$. tuberosum, actin. Statistical analysis was carried out using REST2009 software.
Semiquantitative RT-PCR using RNA extracted from $N$. benthamiana and $S$. tuberosum leaves was carried out using the same qPCR primers reported previously (Ye et al. 2011) and which reside outside the target sequence of the silencing construct. The first-strand cDNA and PCR was performed with the same protocol as described above. The relative measure of gene knockdown was calculated using Image $\mathbf{J}$ (Schneider et al. 2012).

\section{Agroinfiltration, immunoblot analysis, and Image $J$ analysis of data sets.}

Agroinfiltration for delivery of plasmids and infectious clones was performed with a $1-\mathrm{ml}$ needle-free syringe. A. tumefaciens cultures were collected and resuspended in infiltration media adjusted to $\mathrm{OD}_{600}=0.7$ to 1.0 , according to laboratory standard methods (Ye et al. 2011). For PVX-GFP, PlAMV-GFP, and TuMV-GFP systemic GFP could be seen using a hand-held UV lamp between 7 and 10 dpi. For PVY-GFP, it typically took longer than 10 dpi to observe systemic GFP, using a hand-held UV lamp. Negative controls included infiltration of agrobacterium alone or infiltration media alone. In many experiments, agroinfiltrated leaf samples were harvested for RNA for RT-PCR and qRT-PCR as described.

For immunoblot analysis, virus-infected leaves were harvested and total protein was extracted using standard methods (Ye et al. 2011). Total protein was quantified using Bradford reagent (Sigma-Aldrich). For each sample, $30 \mu \mathrm{g}$ of protein was loaded onto $12 \%$ SDS-PAGE gels and was electroblotted to Hybond-P (GE Healthcare). Blots were probed with antisera detecting viral coat proteins obtained from Agdia. Horseradish peroxidase-conjugated secondary antiserum provided by the ECL advanced western blotting kit (GE Healthcare) was used. Blots were developed using FluorChem E (ProteinSimple).

Image $\mathbf{J}$ was used to quantify average integrated density (AvgIntDen) values of bands on agar gels and immunoblots. The scanned image was saved in 16-bit tiff format. The relative density of the peaks within selected areas were calculated by the software and outputted in a table. The density of the selected bands was normalized to a standard background. ANOVA was used to validate the results. The percent gene knockdown for bZIP60 or BI-1 at 5 dpi, i.e., AvgIntDen (treated samples)/AvgIntDen (control samples) $\times 100$, was calculated at 25, 30, and 35 cycles. The averages for controls and treatments were determined across three samples in each experiment. ANOVA was used to validate the results.

Fluorescent images of virus-infected leaves and plants were analyzed by Image $\mathbf{J}$. The drawing tool was used to select the surface area of a leaf or the canopy of the plant producing an area measurement in millimeters. Image $\mathbf{J}$ produced the IntDen values, which equal the area $\times$ mean gray value. The area measurement was optimized by calculating the internal length reference scale and adjustment scaling factors to generate the average scaling factor, which in this case was 1.0. $\mathrm{FV}$ values $=$ IntDen $-($ area $\times$ mean background fluorescence). The average FV for each control and treatment was calculated for six samples at each time point within experiments. For comparisons of inoculated leaves, the FV values for each treatment were reported relative to the control. For comparisons of whole plants, the values were plotted and ANOVA was used to validate the results.

\section{Trypan blue staining of detached leaves.}

Inoculated Arabidopsis leaves were detached, were photographed, and then, were stained using standard trypan blue method (Keogh et al. 1980). Leaves were destained in 95\% ethanol and were mounted in water and were then photographed a second time. 


\section{ACKNOWLEDGMENTS}

Special thanks to S. Namba for valuable conversations. This research was funded by the National Institute of Food and Agriculture PlantAssociated Microbes and Plant-Microbe Interactions award number 2014-67014-21715

\section{LITERATURE CITED}

Adamakis, I. D., Panteris, E., and Eleftheriou, E. P. 2011. The fatal effect of tungsten on Pisum sativum L. root cells: Indications for endoplasmic reticulum stress-induced programmed cell death. Planta 234:21-34.

Bamunusinghe, D., Hemenway, C., Nelson, R., Sanderfoot, A., Ye, C.-M., Silva, A., and Verchot-Lubicz, J. 2009. Analysis of potato virus X replicase and TGBp3 subcellular locations. Virology 393:272-285.

Benali-Furet, N. L., Chami, M., Houel, L., De Giorgi, F., Vernejoul, F., Lagorce, D., Buscail, L., Bartenschlager, R., Ichas, F., Rizzuto, R., and Paterlini-Brechot, P. 2005. Hepatitis C virus core triggers apoptosis in liver cells by inducing ER stress and ER calcium depletion. Oncogene 24:4921-4933.

Bhattacharyya, S., Sen, U., and Vrati, S. 2014. Regulated IRE1-dependent decay pathway is activated during Japanese encephalitis virus-induced unfolded protein response and benefits viral replication. J. Gen. Virol. 95:71-79.

Buytaert, E., Callewaert, G., Hendrickx, N., Scorrano, L., Hartmann, D., Missiaen, L., Vandenheede, J. R., Heirman, I., Grooten, J., and Agostinis, P. 2006. Role of endoplasmic reticulum depletion and multidomain proapoptotic BAX and BAK proteins in shaping cell death after hypericinmediated photodynamic therapy. FASEB J. 20:756-758.

Castillo, K., Rojas-Rivera, D., Lisbona, F., Caballero, B., Nassif, M., Court, F. A., Schuck, S., Ibar, C., Walter, P., Sierralta, J., Glavic, A., and Hetz, C. 2011. BAX inhibitor-1 regulates autophagy by controlling the IRE1alpha branch of the unfolded protein response. EMBO J. 30: 4465-4478.

Chae, H. J., Kim, H. R., Xu, C., Bailly-Maitre, B., Krajewska, M., Krajewski, S., Banares, S., Cui, J., Digicaylioglu, M., Ke, N., Kitada, S., Monosov, E., Thomas, M., Kress, C. L., Babendure, J. R., Tsien, R. Y., Lipton, S. A., and Reed, J. C. 2004. BI-1 regulates an apoptosis pathway linked to endoplasmic reticulum stress. Mol. Cell 15:355-366.

Chang, L. C., Guo, C. L., Lin, Y. S., Fu, H., Wang, C. S., and Jauh, G. Y. 2009. Pollen-specific SKP1-like proteins are components of functional scf complexes and essential for lily pollen tube elongation. Plant Cell Physiol. 50:1558-1572.

Chen, Y., and Brandizzi, F. 2012. AtIRE1A/AtIRE1B and AGB1 independently control two essential unfolded protein response pathways in Arabidopsis. Plant J. 69:266-277.

Chen, Y., and Brandizzi, F. 2013a. Analysis of unfolded protein response in Arabidopsis. Methods Mol. Biol. 1043:73-80.

Chen, Y., and Brandizzi, F. 2013b. IRE1: ER stress sensor and cell fate executor. Trends Cell Biol. 23:547-555.

Chen, S. R., Dunigan, D. D., and Dickman, M. B. 2003. Bcl-2 family members inhibit oxidative stress-induced programmed cell death in Saccharomyces cerevisiae. Free Radic. Biol. Med. 34:1315-1325.

Cotton, S., Grangeon, R., Thivierge, K., Mathieu, I., Ide, C., Wei, T., Wang, A., and Laliberté, J. F. 2009. Turnip mosaic virus RNA replication complex vesicles are mobile, align with microfilaments, and are each derived from a single viral genome. J. Virol. 83:10460-10471.

Deng, Y., Humbert, S., Liu, J. X., Srivastava, R., Rothstein, S. J., and Howell, S. H. 2011. Heat induces the splicing by IRE1 of a mRNA encoding a transcription factor involved in the unfolded protein response in Arabidopsis. Proc. Natl. Acad. Sci. U.S.A. 108:7247-7252.

Deng, Y., Srivastava, R., and Howell, S. H. 2013. Protein kinase and ribonuclease domains of IRE1 confer stress tolerance, vegetative growth, and reproductive development in Arabidopsis. Proc. Natl. Acad. Sci. U.S.A. 110:19633-19638.

Dufresne, P. J., Ubalijoro, E., Fortin, M. G., and Laliberté, J. F. 2008a Arabidopsis thaliana class II poly(A)-binding proteins are required for efficient multiplication of turnip mosaic virus. J. Gen. Virol. 89:23392348.

Dufresne, P. J., Thivierge, K., Cotton, S., Beauchemin, C., Ide, C., Ubalijoro, E., Laliberté, J. F., and Fortin, M. G. 2008b. Heat shock 70 protein interaction with Turnip mosaic virus RNA-dependent RNA polymerase within virus-induced membrane vesicles. Virology 374 217-227.

Duwi Fanata, W. I., Lee, S. Y., and Lee, K. O. 2013. The unfolded protein response in plants: A fundamental adaptive cellular response to internal and external stresses. J. Proteomics 93:356-368.
Gardner, B. M., Pincus, D., Gotthardt, K., Gallagher, C. M., and Walter, P. 2013. Endoplasmic reticulum stress sensing in the unfolded protein response. Cold Spring Harb. Perspect. Biol. 5:a013169.

Grangeon, R., Cotton, S., and Laliberté, J. F. 2010. A model for the biogenesis of Turnip mosaic virus replication factories. Commun. Integr Biol. 3:363-365.

Grangeon, R., Jiang, J., and Laliberté, J. F. 2012a. Host endomembrane recruitment for plant RNA virus replication. Curr. Opin. Virol. 2: 683-690.

Grangeon, R., Agbeci, M., Chen, J., Grondin, G., Zheng, H., and Laliberté, J. F. 2012b. Impact on the endoplasmic reticulum and Golgi apparatus of turnip mosaic virus infection. J. Virol. 86:9255-9265.

Hemetsberger, C., Mueller, A. N., Matei, A., Herrberger, C., Hensel, G., Kumlehn, J., Mishra, B., Sharma, R., Thines, M., Huckelhoven, R., and Doehlemann, G. 2015. The fungal core effector Pep1 is conserved across smuts of dicots and monocots. New Phytol. 206:1116-1126.

Henriquez-Valencia, C., Moreno, A. A., Sandoval-Ibanez, O., Mitina, I., Blanco-Herrera, F., Cifuentes-Esquivel, N., and Orellana, A. 2015 bZIP17 and bZIP60 regulate the expression of BiP3 and other salt stress responsive genes in an UPR-independent manner in Arabidopsis thaliana. J. Cell. Biochem. 116:1638-1645.

Hermand, D. 2006. F-box proteins: More than baits for the SCF? Cell Div. $1: 30$.

Hirota, M., Kitagaki, M., Itagaki, H., and Aiba, S. 2006. Quantitative measurement of spliced XBP1 mRNA as an indicator of endoplasmic reticulum stress. J. Toxicol. Sci. 31:149-156.

Hof, A., Zechmann, B., Schwammbach, D., Huckelhoven, R., and Doehlemann, G. 2014. Alternative cell death mechanisms determine epidermal resistance in incompatible barley-Ustilago interactions. Mol. Plant-Microbe Interact 27:403-414.

Hollien, J., Lin, J. H., Li, H., Stevens, N., Walter, P., and Weissman, J. S. 2009. Regulated Ire1-dependent decay of messenger RNAs in mammalian cells. J. Cell Biol. 186:323-331.

Hong, M. J., Kim, D. Y., and Seo, Y. W. 2013. SKP1-like-related genes interact with various F-box proteins and may form SCF complexes with Cullin-F-box proteins in wheat. Mol. Biol. Rep. 40:969-981.

Humbert, S., Zhong, S., Deng, Y., Howell, S. H., and Rothstein, S. J. 2012. Alteration of the bZIP60/IRE1 pathway affects plant response to ER stress in Arabidopsis thaliana. PLoS One 7:e39023.

Ishikawa, T., Uchimiya, H., and Kawai-Yamada, M. 2013. The role of plant Bax inhibitor-1 in suppressing $\mathrm{H} 2 \mathrm{O} 2$-induced cell death. Methods Enzymol. 527:239-256.

Iwata, Y., and Koizumi, N. 2012. Plant transducers of the endoplasmic reticulum unfolded protein response. Trends Plant Sci. 17:720-727.

Iwawaki, T., and Akai, R. 2006. Analysis of the XBP1 splicing mechanism using endoplasmic reticulum stress-indicators. Biochem. Biophys. Res. Commun. 350:709-715.

Janssen, K., Horn, S., Niemann, M. T., Daniel, P. T., Schulze-Osthoff, K., and Fischer, U. 2009. Inhibition of the ER $\mathrm{Ca}^{2+}$ pump forces multidrugresistant cells deficient in Bak and Bax into necrosis. J. Cell Sci. 122 : 4481-4491.

Ju, H. J., Ye, C. M., and Verchot-Lubicz, J. 2008. Mutational analysis of PVX TGBp3 links subcellular accumulation and protein turnover Virology 375:103-117.

Kang, M. H., and Reynolds, C. P. 2009. Bcl-2 inhibitors: Targeting mitochondrial apoptotic pathways in cancer therapy. Clin. Cancer Res. 15:1126-1132.

Kawai-Yamada, M., Ohori, Y., and Uchimiya, H. 2004. Dissection of Arabidopsis Bax inhibitor-1 suppressing Bax-, hydrogen peroxide-, and salicylic acid-induced cell death. Plant Cell 16:21-32.

Keogh, R., Deverall, B. J., and McLeod, S. 1980. Comparison of histological and physiological responses to Phakopsora pachyrhizi in resistant and susceptible soybean. Trans. Br. Mycol. Soc. 74:329-333.

Khanna, H. K., Paul, J. Y., Harding, R. M., Dickman, M. B., and Dale, J. L. 2007. Inhibition of Agrobacterium-induced cell death by antiapoptotic gene expression leads to very high transformation efficiency of banana. Mol. Plant-Microbe Interact 20:1048-1054.

Komatsu, K., Hashimoto, M., Ozeki, J., Yamaji, Y., Maejima, K., Senshu, H., Himeno, M., Okano, Y., Kagiwada, S., and Namba, S. 2010. Viralinduced systemic necrosis in plants involves both programmed cell death and the inhibition of viral multiplication, which are regulated by independent pathways. Mol. Plant-Microbe Interact 23:283-293.

Komatsu, K., Hashimoto, M., Maejima, K., Shiraishi, T., Neriya, Y., Miura, C., Minato, N., Okano, Y., Sugawara, K., Yamaji, Y., and Namba, S 2011. A necrosis-inducing elicitor domain encoded by both symptomatic and asymptomatic Plantago asiatica mosaic virus isolates, whose expression is modulated by virus replication. Mol. Plant-Microbe Interact 24:408-420. 
Laliberté, J. F., and Sanfacon, H. 2010. Cellular remodeling during plant virus infection. Annu. Rev. Phytopathol. 48:69-91.

Lim, H. S., Vaira, A. M., Reinsel, M. D., Bae, H., Bailey, B. A., Domier, L. L., and Hammond, J. 2010. Pathogenicity of Alternanthera mosaic virus is affected by determinants in RNA-dependent RNA polymerase and by reduced efficacy of silencing suppression in a movementcompetent TGB1. J. Gen. Virol. 91:277-287.

Liu, J. X., and Howell, S. H. 2016. Managing the protein folding demands in the endoplasmic reticulum of plants. New Phytol. 2:418-428.

Liu, J. X., Srivastava, R., and Howell, S. H. 2008. Stress-induced expression of an activated form of AtbZIP17 provides protection from salt stress in Arabidopsis. Plant Cell Environ. 31:1735-1743.

Lu, Y., Yin, M., Wang, X., Chen, B., Yang, X., Peng, J., Zheng, H., Zhao, J., Lin, L., Yu, C., MacFarlane, S., He, J., Liu, Y., Chen, J., Dai, L., and Yan, F. 2016. The unfolded protein response and programmed cell death are induced by expression of Garlic virus X p11 in Nicotiana benthamiana. J. Gen. Virol. 97:1462-1468.

McLean, J. E., Datan, E., Matassov, D., and Zakeri, Z. F. 2009. Lack of Bax prevents influenza A virus-induced apoptosis and causes diminished viral replication. J. Virol. 83:8233-8246.

Moreno, A. A., Mukhtar, M. S., Blanco, F., Boatwright, J. L., Moreno, I., Jordan, M. R., Chen, Y., Brandizzi, F., Dong, X., Orellana, A., and Pajerowska-Mukhtar, K. M. 2012. IRE1/bZIP60-mediated unfolded protein response plays distinct roles in plant immunity and abiotic stress responses. PLoS One 7:e31944.

Nagano, M., Ihara-Ohori, Y., Imai, H., Inada, N., Fujimoto, M., Tsutsumi, N., Uchimiya, H., and Kawai-Yamada, M. 2009. Functional association of cell death suppressor, Arabidopsis Bax inhibitor-1, with fatty acid 2-hydroxylation through cytochrome $b_{5}$. Plant J. 58:122-134.

Nagashima, Y., Mishiba, K., Suzuki, E., Shimada, Y., Iwata, Y., and Koizumi, N. 2011. Arabidopsis IRE1 catalyses unconventional splicing of bZIP60 mRNA to produce the active transcription factor. Sci. Rep. 1:29.

Parra-Rojas, J., Moreno, A. A., Mitina, I., and Orellana, A. 2015. The dynamic of the splicing of bZIP60 and the proteins encoded by the spliced and unspliced mRNAs reveals some unique features during the activation of UPR in Arabidopsis thaliana. PLoS One 10:e0122936.

Paul, J. Y., Becker, D. K., Dickman, M. B., Harding, R. M., Khanna, H. K., and Dale, J. L. 2011. Apoptosis-related genes confer resistance to Fusarium wilt in transgenic 'Lady Finger' bananas. Plant Biotechnol. J. 9:1141-1148.

Ruberti, C., Kim, S. J., Stefano, G., and Brandizzi, F. 2015. Unfolded protein response in plants: One master, many questions. Curr. Opin. Plant Biol. 27:59-66.

Sano, R., and Reed, J. C. 2013. ER stress-induced cell death mechanisms. Biochim. Biophys. Acta 1833:3460-3470.

Sasvari, Z., and Nagy, P. D. 2010. Making of viral replication organelles by remodeling interior membranes. Viruses 2:2436-2442.

Schneider, C. A., Rasband, W. S., and Eliceiri, K. W. 2012. NIH Image to ImageJ: 25 years of image analysis. Nat. Methods 9:671-675.

Scorrano, L., Oakes, S. A., Opferman, J. T., Cheng, E. H., Sorcinelli, M. D., Pozzan, T., and Korsmeyer, S. J. 2003. BAX and BAK regulation of endoplasmic reticulum $\mathrm{Ca}^{2+}$ : A control point for apoptosis. Science 300: 135-139.

Srivastava, R., Deng, Y., Shah, S., Rao, A. G., and Howell, S. H. 2013. BINDING PROTEIN is a master regulator of the endoplasmic reticulum stress sensor/transducer bZIP28 in Arabidopsis. Plant Cell 25:1416-1429.

Sun, Z., Yang, D., Xie, L., Sun, L., Zhang, S., Zhu, Q., Li, J., Wang, X., and Chen, J. 2013. Rice black-streaked dwarf virus $\mathrm{P} 10$ induces membranous structures at the ER and elicits the unfolded protein response in Nicotiana benthamiana. Virology 447:131-139.

Vassilakos, N., Simon, V., Tzima, A., Johansen, E., and Moury, B. 2016. Genetic determinism and evolutionary reconstruction of a host jump in a plant virus. Mol. Biol. Evol. 33:541-553.

Verchot, J. 2011. Wrapping membranes around plant virus infection. Curr. Opin. Virol. 1:388-395.

Watanabe, N., and Lam, E. 2006. Arabidopsis Bax inhibitor-1 functions as an attenuator of biotic and abiotic types of cell death. Plant J. 45: 884-894.

Watanabe, N., and Lam, E. 2008a. Arabidopsis Bax inhibitor-1: A rheostat for ER stress-induced programmed cell death. Plant Signal. Behav. 3: 564-566.

Watanabe, N., and Lam, E. 2008b. BAX inhibitor-1 modulates endoplasmic reticulum stress-mediated programmed cell death in Arabidopsis. J. Biol. Chem. 283:3200-3210.

Watanabe, N., and Lam, E. 2009. Bax Inhibitor-1, a conserved cell death suppressor, is a key molecular switch downstream from a variety of biotic and abiotic stress signals in plants. Int. J. Mol. Sci. 10:31493167.

Weis, C., Pfeilmeier, S., Glawischnig, E., Isono, E., Pachl, F., Hahne, H., Kuster, B., Eichmann, R., and Hückelhoven, R. 2013. Co-immunoprecipitationbased identification of putative BAX INHIBITOR-1-interacting proteins involved in cell death regulation and plant-powdery mildew interactions. Mol. Plant Pathol. 14:791-802.

Williams, B., Verchot, J., and Dickman, M. B. 2014. When supply does not meet demand-ER stress and plant programmed cell death. Front. Plant Sci. 5:211.

Xu, P., Rogers, S. J., and Roossinck, M. J. 2004. Expression of antiapoptotic genes bcl-xL and ced-9 in tomato enhances tolerance to viral-induced necrosis and abiotic stress. Proc. Natl. Acad. Sci. U.S.A. 101:1580515810.

Yamaji, Y., Maejima, K., Komatsu, K., Shiraishi, T., Okano, Y., Himeno, M., Sugawara, K., Neriya, Y., Minato, N., Miura, C., Hashimoto, M., and Namba, S. 2012. Lectin-mediated resistance impairs plant virus infection at the cellular level. Plant Cell 24:778-793.

Yang, X., Srivastava, R., Howell, S. H., and Bassham, D. C. 2016. Activation of autophagy by unfolded proteins during endoplasmic reticulum stress. Plant J. 85:83-95.

Ye, C., and Verchot, J. 2011. Role of unfolded protein response in plant virus infection. Plant Signal. Behav. 6:1212-1215.

Ye, C., Dickman, M. B., Whitham, S. A., Payton, M., and Verchot, J. 2011. The unfolded protein response is triggered by a plant viral movement protein. Plant Physiol. 156:741-755.

Ye, C. M., Chen, S., Payton, M., Dickman, M. B., and Verchot, J. 2013. TGBp3 triggers the unfolded protein response and SKP1-dependent programmed cell death. Mol. Plant Pathol. 14:241-255.

Zhang, L., Chen, H., Brandizzi, F., Verchot, J., and Wang, A. 2015. The UPR branch IRE1-bZIP60 in plants plays an essential role in viral infection and is complementary to the only UPR pathway in yeast. PLoS Genet. 11:e1005164. 